Research Article

\title{
Dynamic Modeling, Response, and Chaos Analysis of 2-DOF Hybrid Mechanism with Revolute Clearances
}

\author{
Xiulong Chen (iD) and Yuefei Tang \\ College of Mechanical and Electronic Engineering, Shandong University of Science and Technology, Qingdao 266590, China \\ Correspondence should be addressed to Xiulong Chen; cxldy99@163.com
}

Received 16 September 2019; Revised 9 December 2019; Accepted 14 December 2019; Published 29 January 2020

Academic Editor: Alvaro Cunha

Copyright (C) 2020 Xiulong Chen and Yuefei Tang. This is an open access article distributed under the Creative Commons Attribution License, which permits unrestricted use, distribution, and reproduction in any medium, provided the original work is properly cited.

\begin{abstract}
Due to the errors arising from machining or assembly, the deformation during movement, and the wear of movement pairs, the clearance will be generated at the kinematic pair of the mechanism, and the service life or working accuracy of the mechanism is reduced. At present, most of the researches are in a simple mechanism with a single clearance, and there are few papers on the complex mechanism, such as the high-speed mechanism which contains multiple clearances. In order to give a computational methodology for the dynamic modeling and analysis of the planar multilink mechanism with multiple degrees of freedom and multiple clearances and master the dynamic characteristics of the planar multilink mechanism, the nonlinear dynamic models of the multiclearance hybrid seven-bar mechanism under different clearance numbers, different clearance values, different clearance positions, and different driving velocities are established and analyzed. The dynamic output response comparison diagram of the mechanism and the collision force diagrams and center trajectory diagrams of the mechanism at the clearance are given. Then, nonlinear dynamics of the mechanism is studied by different clearance values and driving speeds. The corresponding trajectory phase diagrams, Poincare maps, and bifurcation diagrams are given. The above research results provide an effective theoretical basis for the study about the nonlinear dynamic characteristics of the planar link mechanism with clearance and how to compensate or control the clearances.
\end{abstract}

\section{Introduction}

The planar linkage mechanism is capable of generating relative motion by connecting two or more members through a motion pair, which may cause clearances due to errors and wear during assembly or manufacturing. The presence of clearance makes the planar linkage mechanism produce oscillating impact, which reduces the working accuracy and service life of the mechanism. At present, the research on planar mechanisms mainly focuses on simple mechanisms with single clearances. However, these research results do not reflect the actual conditions. Therefore, it is practical to study the dynamic characteristics of complex linkages in consideration of multiple clearances at high speed. At the same time, the nonlinear characteristics can well reflect the law of motion of the mechanical system, so it is necessary to carry out the nonlinear characteristics of the mechanism. Therefore, the study of the nonlinear dynamics of the planar linkage mechanism is also meaningful and necessary.

In recent years, scholars have made a series of innovative achievements in the simple planar linkage mechanism with a single clearance and single degree of freedom. Salahshoor et al. [1] studied the influence of clearance on the vibration characteristics of the crank-slider mechanism with flexible components. Sun et al. [2] used the Lagrange equation to model and simulate the dynamic characteristics of the crankslider mechanism. Xu et al. [3] studied the dynamic characteristics of the planar crank-slider mechanism with deep groove ball bearings. Wang et al. [4] used the improved normal contact collision force and modified Coulomb friction model to analyze the motion characteristics of the crank-slider mechanism under different clearance values. Li et al. [5] established clearance models by the two-state 
contact fluid lubrication model and dry friction model, respectively, and studied the influence of clearance of lubrication hinges on dynamic characteristics of the crankslider mechanism. Abdallah et al. [6] studied the dynamic behavior of a slider-crank mechanism with flexible components and a multijoint clearance by using MSC ADAMS software. Chen et al. [7] studied the influence of clearance and flexible members on the dynamic characteristics of the planar multilink mechanism. Ahmedalbashir et al. [8] studied the dynamic characteristics of the planar four-bar mechanism with clearance and spring. Tian et al. [9] synthesized dynamic analysis and numerical and experimental methods of the multibody mechanical system with clearance or incomplete connection. Li et al. [10] studied the influence of double revolute clearances and harmonic drive on the dynamic characteristics of the crank-slider mechanism. Muvengei et al. [11] considered the double revolute clearances in the planar mechanical system and carried out dynamic analysis. Zheng et al. [12] established a dynamic model of the flexible multilink mechanism with clearance and analyzed ultraprecision press dynamic response by utilizing ADAMS. Varedi-Koulaei et al. [13] studied the defects of dynamic characteristics of parallel manipulators with planar 3-RRR under the condition of reducing clearance. Li et al. [14] studied the dynamic characteristics of the square combination mechanism with clearance. Bai and Zhao [15] modeled and analyzed the dynamic characteristics of the mixed contact model and the modified Coulomb friction model for the planar multibody system with clearance.

At the same time, scholars have studied the dynamic response or nonlinear characteristics of the simple planar linkage mechanism with a single clearance and single degree of freedom. Wang et al. [16] studied the nonlinear dynamic characteristics and chaotic motion phenomena of flexible multibody systems with clearance. Chen et al. [17] studied the static and dynamic characteristics of a new six bar mechanism with a single degree of freedom. Ma and Qian [18] modeled and simulated the planar multibody system with multirevolute clearance joints. Marques et al. [19] considered the joint with spherical clearance and studied its dynamic characteristics. Wang et al. [20] used a new nonlinear contact force model to study the dynamic characteristics of plane mechanical systems with clearances. Farahan et al. [21] modeled the dynamics of the planar fourbar linkage with clearance and analyzed its nonlinear characteristics through the bifurcation diagram. Marques et al. [22] used a variety of friction models to analyze and compare the dynamic analysis of multibody systems. Koshy et al. [23] studied the dynamic characteristics of the mechanical system with dry clearance through the contact force model. Hou et al. [24] studied the chaos identification of the two-rotation one-translation decoupled parallel mechanism in the case of clearance. Zheng et al. [25] studied the dynamic modeling and error analysis of the multilink mechanism considering clearance and spindle bearing structure under flexible conditions. Erkaya et al. [26] studied the dynamic characteristics of partial compliant mechanisms with clearance. Li et al. [27] studied the modeling and control of a plane rigid flexible coupled spacecraft with solar array deployment and joint clearance. Chen et al. [28] studied the chaotic characteristics of the spatial parallel mechanism with spherical clearance.

In summary, there are few researches on the complex planar linkages with multiple degrees of freedom and multiple clearances. Therefore, in this paper, the nonlinear dynamic model of the multiclearance and multi-degree-offreedom complex planar linkage mechanism is established. It not only studies the dynamic response of the multiclearance and multi-degree-of-freedom planar linkage mechanism but also studies the nonlinear characteristics of the mechanism.

In order to give a computational methodology for the dynamic modeling and analysis of the planar multilink mechanism with multiple degrees of freedom and multiple clearances and master the dynamic characteristics, in this paper, the nonlinear dynamic model of the hybrid seven-bar mechanism with multiple clearances is established and analyzed, and the corresponding dynamic response, phase diagram, and Poincare map are given. Firstly, the Lankarani-Nikravesh model and the Coulomb model are used to mathematically model the normal collision force and the tangential friction force, respectively, and then the Lagrange equation is used to establish the dynamic equation of the planar linkage mechanism under multiple clearances. The dynamic characteristics of the hybrid drive seven-bar linkage mechanism are analyzed by the number of different clearances, different clearance values, different clearance positions, and different driving velocities. The nonlinear dynamic characteristics of the mechanism are studied by Poincare mapping and bifurcation diagrams with different clearance values and driving speeds. The above research results provide an effective theoretical basis for the study about the nonlinear dynamic characteristics of the planar link mechanism with clearance and how to compensate or control the clearance.

\section{Establishment of the Contact Force Model}

\subsection{Establishment of the Revolute Clearance Motion Model.} When modeling the motion of revolute clearance, the bearings and shafts in the motion pair are described geometrically. At this time, the bearings and shafts in the motion pair are regarded as independent components, and the bearings and shafts are assumed to be ideal circles. The motion model of the revolute clearance is shown in Figure 1.

According to Figure 1, the eccentricity vector between the connecting center of the bearing and the connecting center of the shaft can be expressed as

$$
\mathbf{e}_{i}=\mathbf{r}_{2}^{O}-\mathbf{r}_{1}^{O}
$$

where $O_{1}$ and $\mathbf{r}_{1}^{O}$ represent the position vectors in the center and coordinate system of the bearing, respectively, and $\mathrm{O}_{2}$ and $\mathbf{r}_{2}^{\mathrm{O}}$ represent the position vectors in the center and coordinate system of the shaft.

The unit vector of the eccentricity vector can be expressed as 


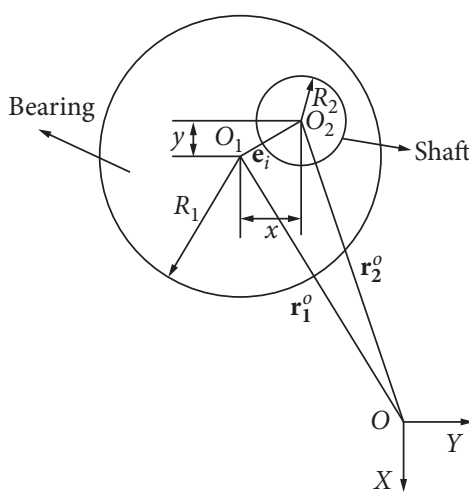

(a)

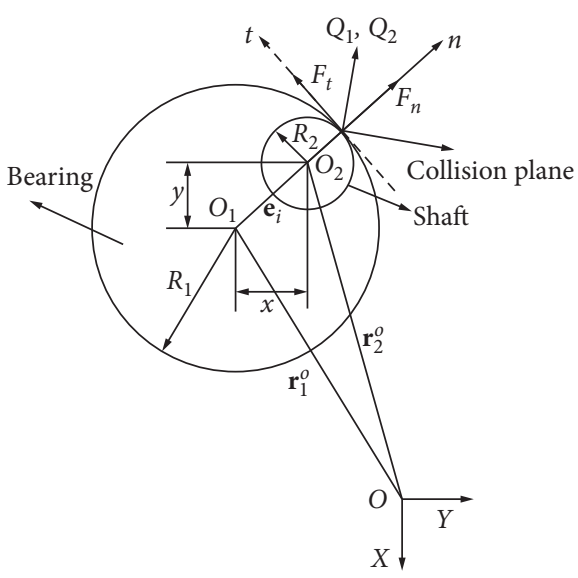

(b)

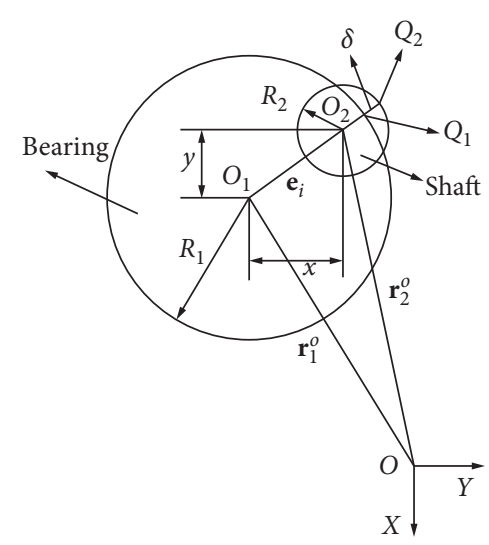

(c)

Figure 1: Bearing and shaft clearance model. (a) Free flight mode. (b) Contact mode. (c) Impact mode.

$$
\mathbf{n}=\frac{\mathbf{e}_{i}}{e_{i}}
$$

where $e_{i}=\sqrt{\mathbf{e}_{i}^{\mathrm{T}} \mathbf{e}_{i}}$ denotes the size of the eccentric vector.

The position vector of the collision point in the coordinate system can be expressed as

$$
\left\{\begin{array}{l}
\mathbf{r}_{1}^{Q}=\mathbf{r}_{1}^{O}+R_{1} \mathbf{n}, \\
\mathbf{r}_{2}^{Q}=\mathbf{r}_{2}^{O}+R_{2} \mathbf{n},
\end{array}\right.
$$

where $Q_{1}$ denotes the collision point of the bearing and $Q_{2}$ denotes the collision point of the shaft.

By deriving the first order of time from equation (3), the velocity of the bearing and shaft at the contact point can be expressed as

$$
\left\{\begin{array}{l}
\dot{\mathbf{r}}_{1}^{Q}=\dot{\mathbf{r}}_{1}^{O}+R_{1} \dot{\mathbf{n}}, \\
\dot{\mathbf{r}}_{2}^{Q}=\dot{\mathbf{r}}_{2}^{O}+R_{2} \dot{\mathbf{n}},
\end{array}\right.
$$

where $\dot{\mathbf{n}}=\left(\dot{\mathbf{e}}_{i} e_{i}-\dot{e}_{i} \mathbf{e}_{i}\right) / e_{i}^{2}$.

The relative velocities in normal and tangential directions (at the contact points of bearings and shafts) can be expressed as

$$
\left\{\begin{array}{l}
v_{n}=\left(\dot{\mathbf{r}}_{2}^{Q}-\dot{\mathbf{r}}_{1}^{\mathrm{Q}}\right)^{\mathrm{T}} \mathbf{n}, \\
v_{t}=\left(\dot{\mathbf{r}}_{2}^{\mathrm{Q}}-\dot{\mathbf{r}}_{1}^{\mathrm{Q}}\right)^{\mathrm{T}} \mathbf{t} .
\end{array}\right.
$$

The penetration depth between the shaft and the bearing can be expressed as

$$
\delta=e_{i}-r
$$

where $r=R_{1}-R_{2}$ represents the clearance value, in which $R_{1}$ represents the radius of the bearing and $R_{2}$ represents the radius of the shaft, respectively.

Through the geometric relationship between the shaft and the bearing, the contact conditions of the collision can be obtained as follows:

$$
\left\{\begin{array}{l}
\delta=e_{i}-r<0, \\
\delta=e_{i}-r=0 \\
\delta=e_{i}-r>0
\end{array}\right.
$$

If $\delta=e_{i}-r<0$, the shaft and the bearing do not collide. If $\delta=e_{i}-r=0$, the shaft and the bearing are in contact or disengagement.

If $\delta=e_{i}-r>0$, the shaft and the bearing collide and produce elastic deformation.

2.2. Establishment of the Normal Contact Force Model. Since the dynamic model established by the Hertz contact force model of the pure elastic model does not meet the actual work of collision, on the basis of the elastic force and energy dissipation caused by impact, the normal collision contact force is obtained by modifying the Hertz contact force model by Lankarani-Nikravesh. According to the literature $[4,29]$, it can be expressed as follows:

$$
F_{n}=K \delta^{n}+D \dot{\delta}
$$

where $K$ is a nonlinear stiffness coefficient, and $K=\left(4 / 3\left(\delta_{1}+\delta_{2}\right)\right) \sqrt{\left(R_{1} R_{2} / R_{1}+R_{2}\right)}$, in which $\delta_{1}=$ $\left(1-v_{1}^{2} / E_{1}\right)$ and $\delta_{2}=\left(1-v_{2}^{2} / E_{2}\right) . D$ is a modified damping coefficient, and $D=\left(3 K\left(1-c_{e}^{2}\right) \delta^{n} / 4 \dot{\delta}_{0}\right) \cdot v_{1}$ and $v_{2}$ represent Poisson's ratio of the bearing and shaft. $E_{1}$ and $E_{2}$ represent the elastic modulus of the bearing and shaft. Because the force exponent is determined by the geometrical characteristics of the material contacting the rigid body and the contact area, and the material is metal, according to the literature $[30,31]$, the force exponent $n=1.5$.

2.3. Establishment of the Tangential Contact Force Model. The Coulomb model is often used when considering tangential friction caused by friction. In order to obtain stable and accurate values, according to the literature [32], tangential friction can be expressed as 


$$
F_{t}=-c_{f} c_{d} F_{n} \frac{v_{t}}{\left|v_{t}\right|}= \begin{cases}0 & v_{t} \leq v_{0}, \\ -c_{f} \frac{v_{t}-v_{0}}{v_{1}-v_{0}} F_{n} & v_{0} \leq v_{t} \leq v_{1}, \\ -c_{f} c F_{n} & v_{t} \geq v_{0},\end{cases}
$$

where $c_{f}$ is the friction coefficient, $c_{d}$ represents the dynamic correction coefficient, and $v_{0}$ and $v_{1}$ represent extreme static and dynamic friction velocities, respectively.

Normal contact force and tangential friction force at clearance can be obtained by collision. Equivalent force and moment can be expressed as

$$
\left\{\begin{array}{l}
f_{12}=F_{n} n+F_{t} t=\left[\begin{array}{ll}
f_{12}^{x} & f_{12}^{y}
\end{array}\right]^{\mathrm{T}} \\
f_{21}=-f_{12} \\
\operatorname{mom}_{12}=-\left(y_{1}^{Q_{1}}-y_{1}\right) f_{12}^{x}+\left(x_{1}^{Q_{1}}-x_{1}\right) f_{12}^{y} \\
\operatorname{mom}_{21}=-\left(y_{2}^{Q_{2}}-y_{2}\right) f_{21}^{x}+\left(x_{2}^{Q_{2}}-x_{2}\right) f_{21}^{y} .
\end{array}\right.
$$

\section{Dynamic Modeling of the Hybrid Driven Seven-Bar Mechanism with Clearances}

3.1. Characteristics of the Hybrid Driven Seven-Bar Mechanism with Clearances. From Figure 2, it can be seen that the hybrid drive seven-bar mechanism (each rod is homogeneous) consists of a frame, crank 2, connecting rod 3, triangle plate 4 , connecting rod 5 , slider 6 , and crank 7 . Crank 2 and crank 7 are connected with the frame through hinges. Connecting rod 3 is connected with crank 2 by a revolute pair, and triangle plate 4 is connected with connecting rod 3 , connecting rod 5 , and crank 7 , respectively, by a revolute pair. The other end of connecting rod 5 is connected with slider 6 through a revolute pair. Slider 6 is located in the fixed guide rail. Among them, crank 2, connecting rod 3 and triangle plate 4 , connecting rod 5 are connected through clearances $\mathrm{A}$ and $\mathrm{C}$ of revolute pairs, respectively. The degree of freedom of the hybrid seven-bar mechanism is 2 in the ideal state. Hybrid driving press mainly combines the traditional motor and servo motor with two cranks of the mechanism. The power input of the mechanism mainly depends on the traditional motor, while the motion adjustment during the operation mainly depends on the servo motor. The traditional motor with higher power and servo motor with lower power can improve the accuracy of the speed and position of the slider, and the output response curve of the slider can be more diversified by adding three pairs of components. The hybrid drive seven-bar mechanism can synthesize different motion laws of the linkage mechanism and realize the high speed and high precision. Therefore, the mechanism is used in heavy machinery and precision machinery industries widely.

The detailed design parameters of the institution are shown in Table 1.
3.2. Flow Chart for Solving Clearance of the Hybrid Driven Seven-Bar Mechanism with Clearances. Because it is nonlinear, the numerical method is used instead of the analytical method to solve the problem. The flow chart of the solution is shown in Figure 3.

When the local coordinate system is established for the centroid of each component of the mechanism, the global generalized coordinates corresponding to each component can be expressed as

$$
\mathbf{q}_{i}=\left(\begin{array}{lll}
x_{i} & y_{i} & \theta_{i}
\end{array}\right)^{\mathrm{T}}(i=2,3,4,5,6,7),
$$

where $x_{i}$ and $y_{i}$ represent the centroid coordinates of components in $x$ and $y$ directions in the global coordinate system and $\theta_{i}$ represent the angles of components $i$ in the global coordinate system.

According to the global generalized coordinate formula (11), the generalized velocity and the generalized acceleration of each component of the mechanism can be expressed as

$$
\begin{aligned}
& \dot{\mathrm{q}}_{i}=\left(\begin{array}{lll}
\dot{x}_{i} & \dot{y}_{i} & \dot{\theta}_{i}
\end{array}\right)^{\mathrm{T}}(i=2,3,4,5,6,7), \\
& \ddot{\mathrm{q}}_{i}=\left(\begin{array}{lll}
\ddot{x}_{i} & \ddot{y}_{i} & \ddot{\theta}_{i}
\end{array}\right)^{\mathrm{T}}(i=2,3,4,5,6,7) .
\end{aligned}
$$

The constraint equation for the hybrid seven-bar linkage with multiple clearances can be expressed as follows:

$$
\mathbf{\Phi}(\mathbf{q}, t)=\left[\begin{array}{c}
h x-\left(x_{2}+L_{s 2} \cos \theta_{2}\right) \\
h y-\left(y_{2}+L_{s 2} \sin \theta_{2}\right) \\
x_{3}-L_{s 3} \cos \theta_{3}-\left(x_{4}-L_{s 41} \cos \left(\theta_{4}+\beta_{1}-\pi\right)\right) \\
y_{3}-L_{s 3} \sin \theta_{3}-\left(y_{4}-L_{s 41} \sin \left(\theta_{4}+\beta_{1}-\pi\right)\right) \\
x_{7}+L_{s 7} \cos \theta_{7}-\left(x_{4}+L_{s 42} \cos \left(\theta_{4}-\beta-\pi\right)\right) \\
y_{7}+L_{s 7} \sin \theta_{7}-\left(y_{4}+L_{s 42} \sin \left(\theta_{4}-\beta-\pi\right)\right) \\
x_{6}-\left(x_{5}-L_{s 5} \cos \theta_{5}\right) \\
y_{6}-\left(y_{5}-L_{s 5} \sin \theta_{5}\right) \\
x_{6}-h x \\
\theta_{6}-90^{\circ} \\
x_{7}-L_{s 7} \cos \theta_{7} \\
y_{7}-L_{s 7} \sin \theta_{7} \\
\theta_{7}-\omega_{7} t+51.18^{\circ} \\
\theta_{2}-\omega_{2} t+119.27^{\circ}
\end{array}\right]=0 .
$$

According to constraint equation formula (13), the velocity of the constraint equation of mechanism can be obtained by the first derivation and can be expressed as

$$
\Phi_{q} \dot{q}=-\Phi_{t} \equiv \mathbf{v}
$$

where $\Phi_{q}=\partial \Phi / \partial \mathbf{q}$ is the Jacobian matrix and $\Phi_{t}=\partial \Phi / \partial t$ is the first derivative of time for the constraint equation.

According to constraint equation formula (13), the acceleration of the constraint equation of mechanism is obtained by the second derivation and can be expressed as

$$
\Phi_{q} \ddot{q}=-\left(\Phi_{q} \dot{q}\right)_{q} \dot{q}-2 \Phi_{q t} \dot{q}-\Phi_{t t} \equiv \gamma \text {. }
$$




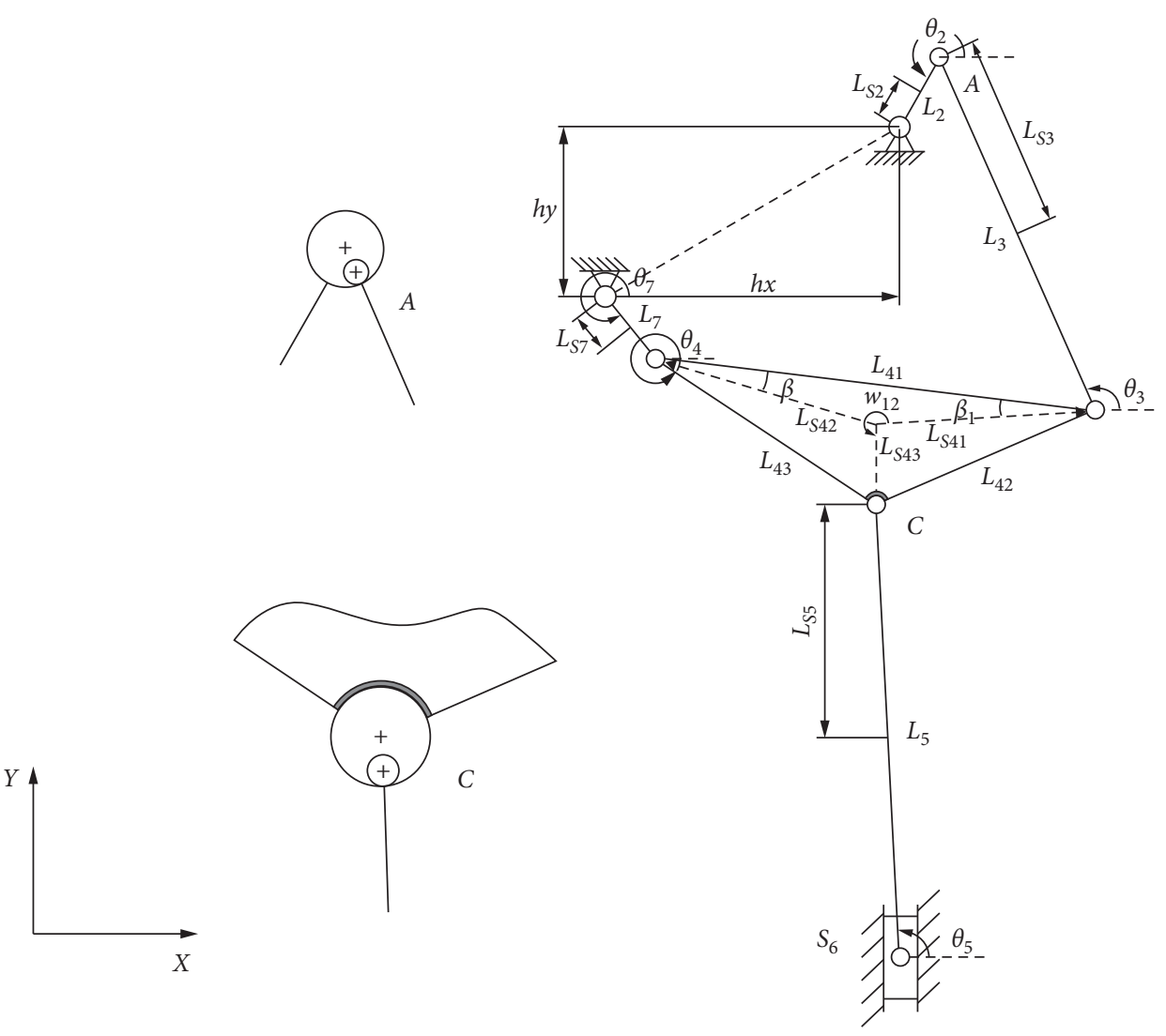

Figure 2: Hybrid driven seven-bar mechanism.

TABLE 1: Design parameters of the hybrid driven seven-bar mechanism.

\begin{tabular}{lccc}
\hline Designed parameter & Parameter values & Designed parameter & Parameter values \\
\hline Initial angle of the frame $\left(^{\circ}\right)$ & 30 & Ls41 (m) & 0.194 \\
Initial angle of crank 2 $\left(^{\circ}\right)$ & -51.18 & $L s 42(\mathrm{~m})$ & 0.202 \\
Initial angle of crank 7 $\left(^{\circ}\right)$ & -119.27 & Ls43 (m) & 0.072 \\
$\beta\left({ }^{\circ}\right)$ & 9.95 & $L s 5(\mathrm{~m})$ & 0.219 \\
$\beta_{12}\left({ }^{\circ}\right)$ & 10.39 & $L s 6(\mathrm{~m})$ & - \\
$\theta_{1}\left({ }^{\circ}\right)$ & 30 & $L s 7(\mathrm{~m})$ & 0.035 \\
$\omega_{12}\left({ }^{\circ}\right)$ & 226.71 & $h x(\mathrm{~m})$ & 0.259 \\
$L s 2(\mathrm{~m})$ & 0.035 & $h y(\mathrm{~m})$ & 0.150 \\
$L s 3(\mathrm{~m})$ & 0.170 & & \\
\end{tabular}

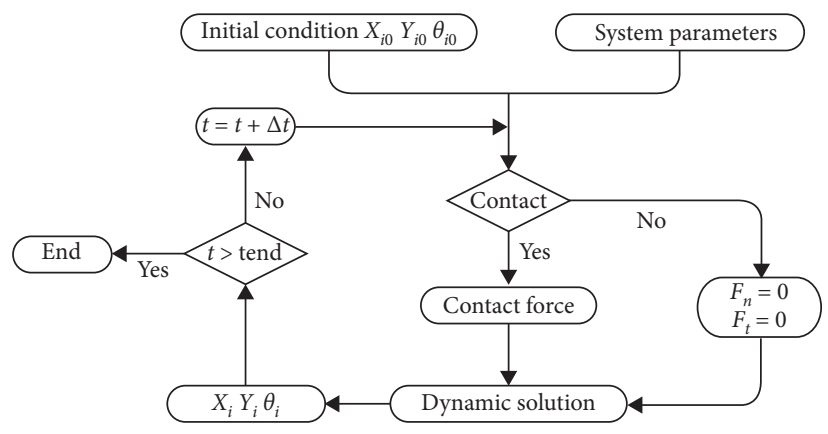

FIGURE 3: Dynamic solution flow of the hybrid driven seven-bar mechanism with clearances. 
According to the constraint equation and acceleration of the mechanism, the dynamic equation can be expressed as

$$
\mathbf{M} \ddot{q}+\Phi_{q}^{\mathrm{T}} \lambda=\mathbf{g}
$$

where $\mathbf{M}$ represents the mass matrix of each component of the mechanism, $\lambda$ is the Lagrange multiplier column vector, and $\mathbf{g}$ is the generalized external force column vector of the mechanism.

When the mechanism does not consider elastic deformation, the dynamic equation of the mechanism can be expressed as

$$
\left(\begin{array}{cc}
\mathbf{M} & \Phi_{q}^{\mathrm{T}} \\
\Phi_{q} & 0
\end{array}\right)\left(\begin{array}{l}
\ddot{q} \\
\lambda
\end{array}\right)=\left(\begin{array}{l}
\mathbf{g} \\
\gamma
\end{array}\right)^{\mathrm{T}}
$$

In order to obtain stable calculation results, kinematic displacement constraints and velocity constraints of the mechanism are introduced into the equation and can be expressed as

$$
\gamma^{\prime}=\gamma-2 \alpha \dot{\Phi}-\beta^{2} \Phi
$$

where $\alpha=50$ and $\beta=50$ are the stability coefficients and $\dot{\Phi}=\mathrm{d} \Phi / \mathrm{d} t$.

According to the literature [7], a stable dynamic equation is obtained and can be expressed as

$$
\left(\begin{array}{cc}
\mathbf{M} & \Phi_{q}^{\mathrm{T}} \\
\Phi_{q} & 0
\end{array}\right)\left(\begin{array}{l}
\ddot{q} \\
\lambda
\end{array}\right)=\left(\begin{array}{c}
\mathbf{g} \\
\gamma^{\prime}
\end{array}\right)^{\mathrm{T}}
$$

\section{Dynamic Response Analysis of the Hybrid Driven Seven-Bar Mechanism with Clearances}

Most of the studies on the dynamic characteristics of the multiclearance and multi-degree-of-freedom hybrid drive linkage mechanism are at two cranks or crank-slider locations, while few studies have been done on the triangle panel in the mechanism with clearance. At the same time, in order to better reflect the influence of the crank-triangle plate on the dynamic output response, in this paper, the clearance is considered at crank $\mathrm{A}$ and triangle panel $\mathrm{C}$ of the hybrid seven-bar linkage, and the dynamic model of the hybrid seven-bar linkage is established by Runge-Kutta. The effects of different clearances, different clearance positions, and different clearance values on the dynamic response of the mechanism are studied.

\subsection{System Parameters of the Hybrid Driven Seven-Bar} Mechanism with Clearances. According to the dynamic model, hinges of the mechanism are used as the constraint condition, the fluctuation of the output response curve of the slider pair is minimized as the optimization target, and the mechanism is optimized. The simulation parameters and design parameters are obtained which are shown in Table 2. According to the literature [24], the rotational clearance parameters in Table 3 are referenced.
4.2. Influence of Different Clearance Positions on the Dynamic Characteristics. In this section, the effects of different clearance positions on the dynamics of a seven-bar mechanism are discussed. The clearance value of the hybrid driven seven-bar mechanism with clearances in this section is $0.05 \mathrm{~mm}$, and the corresponding speeds of the two cranks are set to $\omega_{2}=-2 \pi(\mathrm{rad} / \mathrm{s}), \omega_{7}=2 \pi(\mathrm{rad} / \mathrm{s})$. Seven-bar mechanisms with single clearance A (located at crank 2 and connecting rod 3 ) and single clearance $\mathrm{C}$ (located at triangle plate 4 and connecting rod 5) are studied and analyzed, respectively. The displacement, velocity, acceleration, collision force curve at clearance, and shaft center trajectory of the seven-bar mechanism with a single clearance are obtained.

From the displacement comparison figure in Figure 4, it can be seen that the displacement output response curve of the slider of the seven-bar mechanism will lag behind that of the ideal state at clearances $\mathrm{A}$ and $\mathrm{C}$. According to the velocity comparison chart in Figure 5, the fluctuation trend of the velocity output response curve of the slider of the seven-bar mechanism at clearances $A$ and $C$ occurs on the ideal response curve. According to the acceleration contrast figure in Figure 6, when the clearance of the seven-bar mechanism is considered at $C$, the peak value of the acceleration output response curve of the slider appears at $0.0025 \mathrm{~s}$ and the corresponding peak value of acceleration is $227 \mathrm{~m} / \mathrm{s}^{2}$, and when the clearance of the seven-bar mechanism is considered at $\mathrm{A}$, the peak value of the acceleration output response curve of the slider appears at $0.0042 \mathrm{~s}$ and the peak value of the acceleration is $94.8 \mathrm{~m} / \mathrm{s}^{2}$. Therefore, the peak value at clearance $C$ is larger than that at clearance $A$, which shows the numerical fluctuation at clearance $A$ is smaller. According to the collision force contrast figure in Figure 7, when the clearance is considered at $\mathrm{C}$, the collision force of the seven-bar mechanism vibrates violently in $[0 \mathrm{~s}$, $0.0394 \mathrm{~s}$ ] and the peak value is $41.22 \mathrm{~N}$ at $0.0025 \mathrm{~s}$, and when the clearance is considered at $\mathrm{A}$, the collision force of the seven-bar mechanism vibrates violently in $[0 \mathrm{~s}, 0.07 \mathrm{~s}]$ and the peak value is $93.56 \mathrm{~N}$ at $0.0042 \mathrm{~s}$. Therefore, the peak collision force at clearance $\mathrm{A}$ is larger than that at clearance $\mathrm{C}$, and the time of violent vibration at clearance $\mathrm{A}$ is longer than that at clearance $\mathrm{C}$. Through the shaft center trajectory in Figure 8, it can be seen that the collision range of clearance $\mathrm{A}$ is larger and the trajectory is more chaotic.

4.3. Influence of the Number of Clearances on the Dynamic Characteristics. In this section, the clearance value is set to $0.05 \mathrm{~mm}$, and the corresponding speeds of the two cranks are set to $\omega_{2}=-2 \pi(\mathrm{rad} / \mathrm{s}), \omega_{7}=2 \pi(\mathrm{rad} / \mathrm{s})$. The displacement, velocity, acceleration, collision force curve at clearance, and shaft center trajectory of the seven-bar mechanism with a single clearance and double clearances are obtained.

From the displacement contrast figure in Figure 9, it can be seen that the displacement output response curve of the slider of the seven-bar mechanism will lag behind the displacement under the ideal condition with clearance. According to the velocity comparison chart in Figure 10, the velocity output response curve of the slider of the seven-bar 
TABLE 2: Geometric and inertial parameters of the hybrid driven seven-bar mechanism.

\begin{tabular}{|c|c|c|c|}
\hline Component & Length $L(\mathrm{~m})$ & Mass $m(\mathrm{~kg})$ & Moment of inertia $J\left(\mathrm{~kg} \cdot \mathrm{m}^{2}\right)$ \\
\hline Crank 2 & 0.070 & 0.02429 & $5.396 \times 10^{-4}$ \\
\hline Connecting rod 3 & 0.340 & 0.10854 & $1.1 \times 10^{-3}$ \\
\hline Triangular panel $L_{41}$ & 0.390 & & \\
\hline Triangular panel $L_{42}$ & 0.210 & 0.45026 & $3.779 \times 10^{-3}$ \\
\hline Triangular panel $L_{43}$ & 0.233 & & \\
\hline Connecting rod 5 & 0.40 & 0.12723 & $1.771 \times 10^{-3}$ \\
\hline Slider 6 & - & 0.02875 & - \\
\hline Crank 7 & 0.070 & 0.02429 & $5.396 \times 10^{-4}$ \\
\hline
\end{tabular}

TABLE 3: Revolute clearance joint parameters.

\begin{tabular}{lc}
\hline Designed parameter & Parameter values \\
\hline Bearing radius $R_{1}(\mathrm{~mm})$ & 15 \\
Restitution coefficient $c_{e}$ & 0.9 \\
Elastic modulus $E 1, E 2(\mathrm{GPa})$ & 200 \\
Poisson's ratio $v_{1}$ & 0.3 \\
Poisson's ratio $v_{2}$ & 0.3 \\
Integral step $d_{t}(\mathrm{~s})$ & 0.0001 \\
Integral step error $\delta_{m}(\mathrm{~m})$ & 0.000001 \\
Limit velocity $v_{1}(\mathrm{~m} / \mathrm{s})$ & 0.001 \\
Limit velocity $v_{0}(\mathrm{~m} / \mathrm{s})$ & 0.0001 \\
Force exponent $n$ & 1.5
\end{tabular}

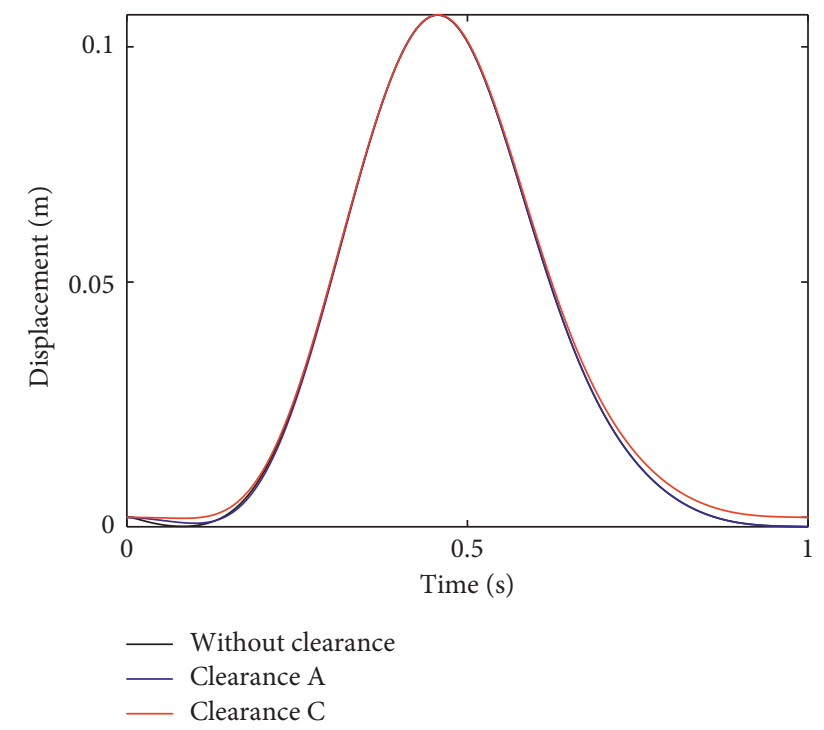

FIGURE 4: Displacement of the slider under different clearance positions.

mechanism is no longer fluctuating in varying degrees on the basis of the ideal curve but shows the zigzag wave. This shows that the more the clearances, the greater the velocity error. According to the acceleration contrast figure in Figure 11, when the clearance value is $0 \mathrm{~mm}$, the peak value of the output response curve of the slider acceleration appears at $0.2138 \mathrm{~s}$ and the peak value of the acceleration is $3.592 \mathrm{~m} / \mathrm{s}^{2}$. When considering a single clearance, the peak value of the output response curve of the slider's acceleration appears at $0.0042 \mathrm{~s}$ and the peak value of the acceleration is

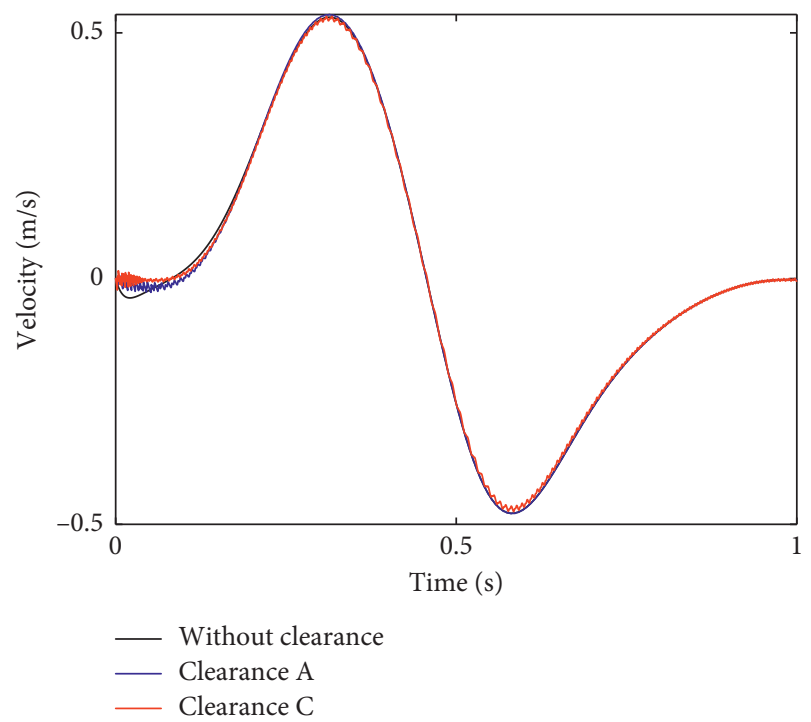

FIgURE 5: Velocity of the slider under different clearance positions.

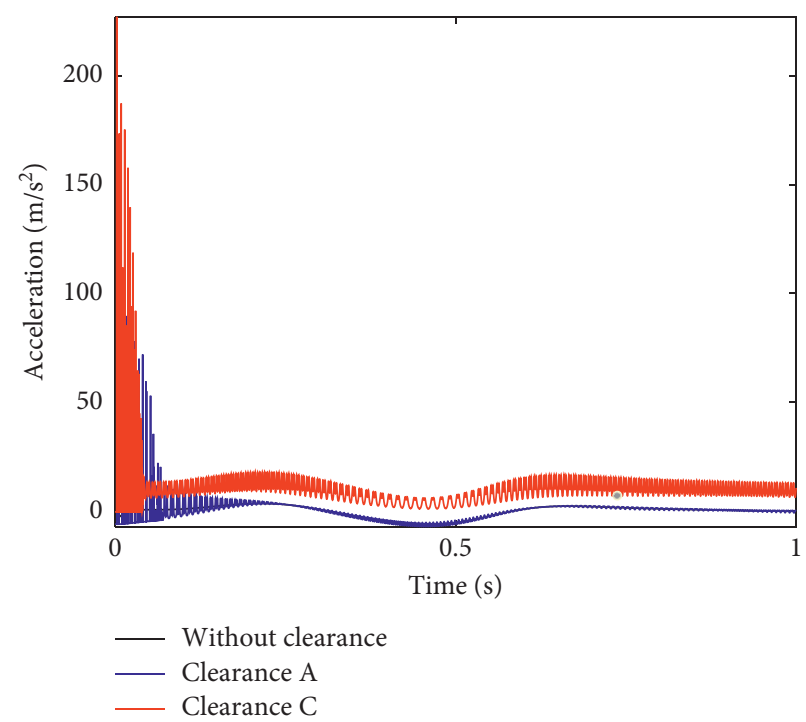

FIGURE 6: Acceleration of the slider under different clearance positions.

$94.8 \mathrm{~m} / \mathrm{s}^{2}$. When the double clearances are considered, the peak value of the output response curve of the slider acceleration appears at $0.0117 \mathrm{~s}$ and the peak value of the 


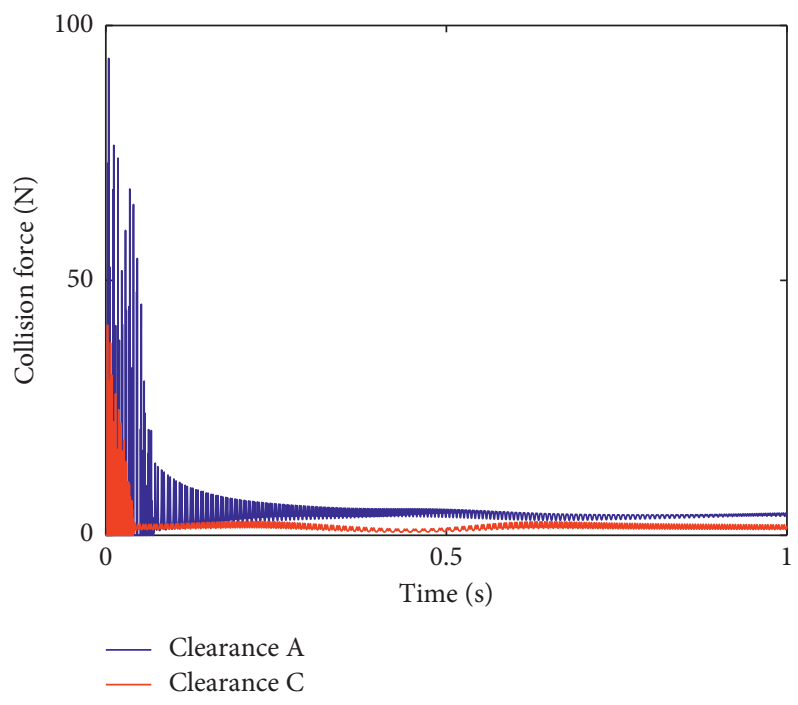

FIgURe 7: Collision force under different clearance positions.

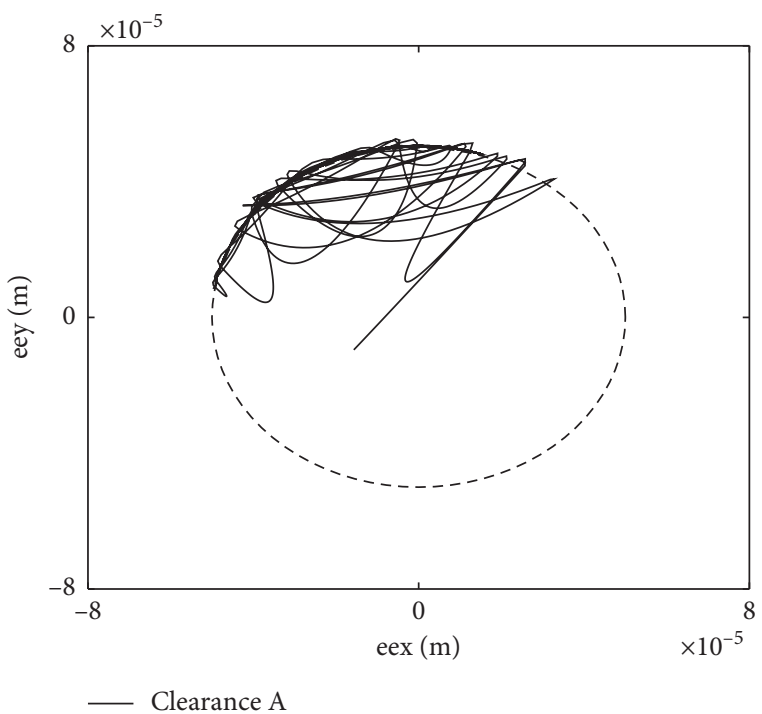

(a)

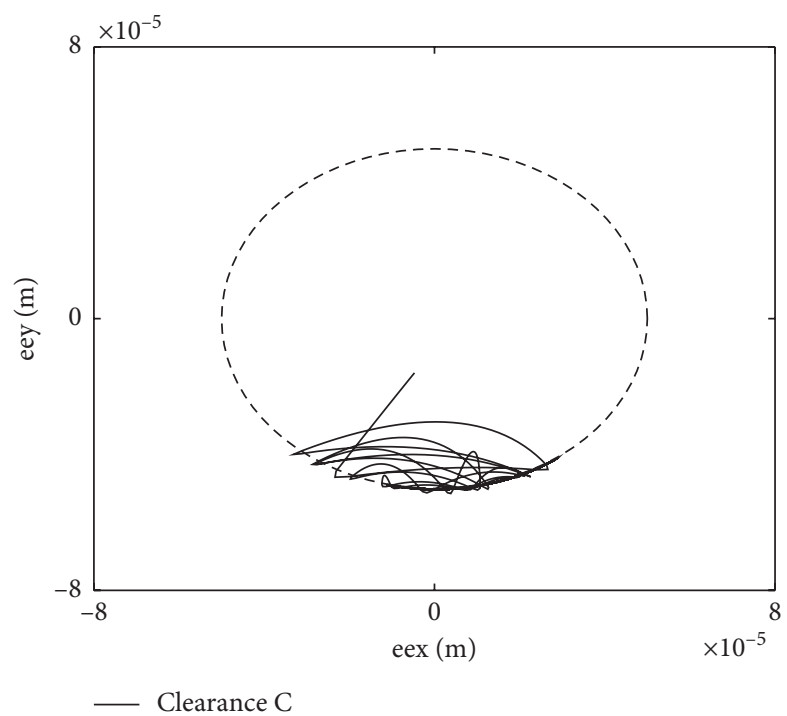

(b)

Figure 8: Shaft center motion trajectory at (a) clearance A and (b) clearance C.

acceleration at this time is $310.8 \mathrm{~m} / \mathrm{s}^{2}$. Therefore, when the number of clearances increases, the acceleration peak value increases. According to the collision force contrast figure in Figure 12, when the collision force at clearance A with a single clearance is considered to collide violently within $[0 \mathrm{~s}$, $0.07 \mathrm{~s}]$, the peak value is $93.56 \mathrm{~N}$ at $0.0042 \mathrm{~s}$, and when the collision force at clearance A with double clearances is considered intense collision within $[0 \mathrm{~s}, 0.5 \mathrm{~s}]$, the peak value is $98.97 \mathrm{~N}$ at $0.0042 \mathrm{~s}$. Therefore, when the number of clearances increases, the peak collision force increases and the collision intensifies. By comparing the trajectories (a) and (b) of the center of the shaft in Figure 13, it can be seen that when the clearance number is 1 , the trajectories of the shaft at clearance A are relatively chaotic, while when the clearance number is 2 , the collision points at clearance $\mathrm{A}$ are relatively concentrated and the collision trajectories are relatively stable. By comparing the trajectories (c) and (d) of the center of the shaft in Figure 13, it can be seen that when the clearance number is 1 , the collision points at clearance A are relatively concentrated and the collision trajectories are relatively stable, while when the clearance number is 2 , the trajectories of the axis at clearance $\mathrm{C}$ are relatively chaotic.

4.4. Influence of Different Clearance Values at the Same Position on the Dynamic Characteristics. In this section, the influence of different clearance values at the same position on the dynamic characteristics of the seven-bar mechanism is discussed. The seven-bar mechanism sets four clearance values for clearance $A$, which are $0.03 \mathrm{~mm}, 0.05 \mathrm{~mm}$ $0.07 \mathrm{~mm}$, and $0.09 \mathrm{~mm}$, respectively. At the same time, the corresponding speed of the two cranks is set to $\omega_{2}=-2 \pi(\mathrm{rad} / \mathrm{s}), \omega_{7}=2 \pi(\mathrm{rad} / \mathrm{s})$. The displacement, velocity, acceleration, collision force curve at clearance, and shaft 


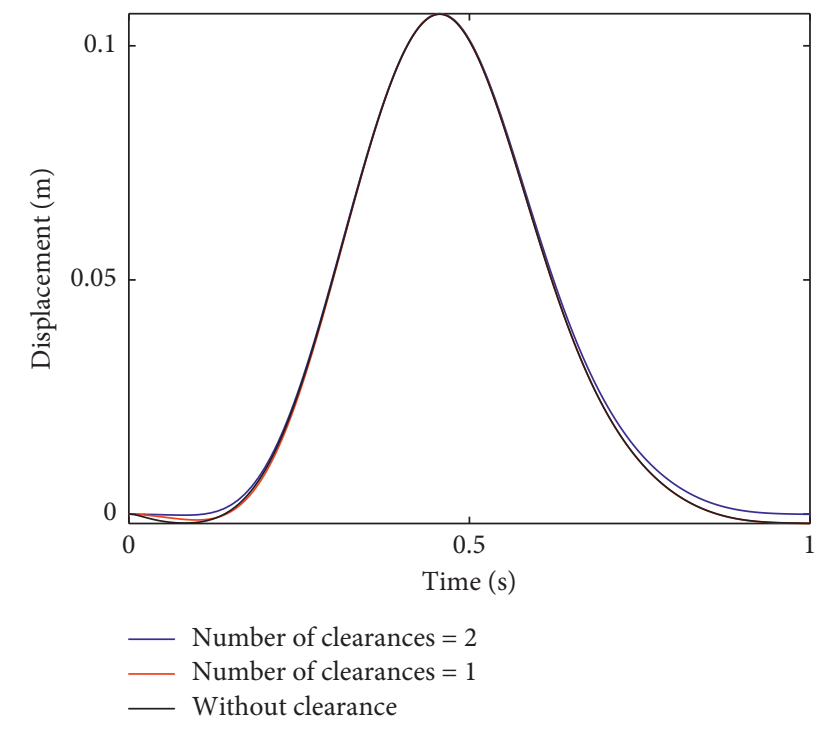

FIGURE 9: Displacement of the slider with different numbers of clearances.

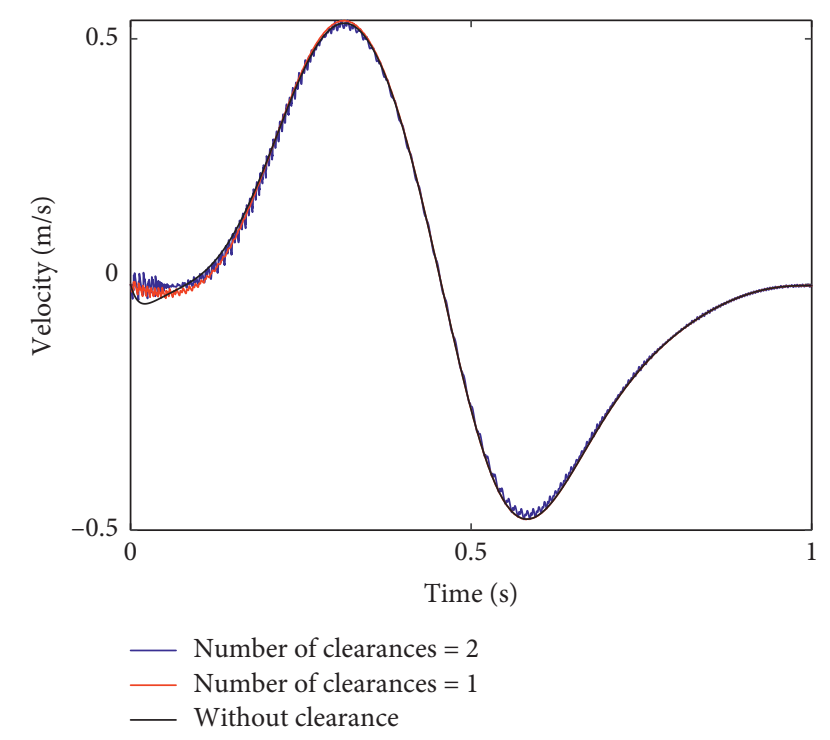

Figure 10: Velocity of the slider with different numbers of clearances.

center trajectory of the seven-bar mechanism with different clearance values are obtained.

The displacement comparison diagram in Figure 14 shows that when the clearance value increases, the lag trend of the displacement output response curve of the seven-bar mechanism slider becomes more and more obvious. According to the velocity contrast chart in Figure 15, with the increase of the clearance value, the output response curve fluctuates in different degrees, and the fluctuation trend is more and more obvious. Therefore, when the clearance value increases, the more obvious the change of slider speed is, the lower the output precision is. According to the acceleration contrast figure in Figure 16, when the clearance value of the seven-bar mechanism is $0.03 \mathrm{~mm}$, the peak value of the output response curve of the slider acceleration appears at $0.0086 \mathrm{~s}$

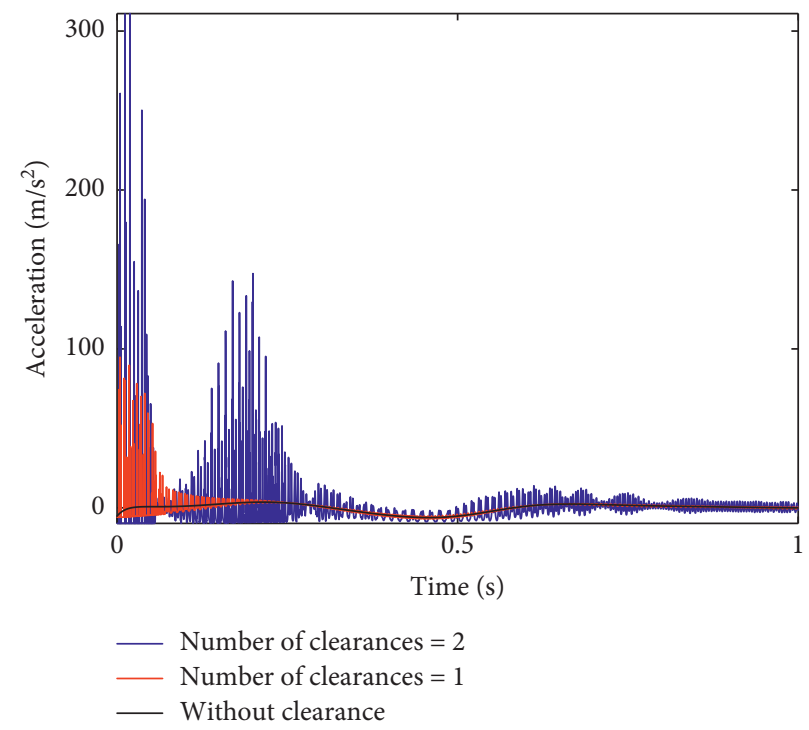

FIGURE 11: Acceleration of the slider with different numbers of clearances.

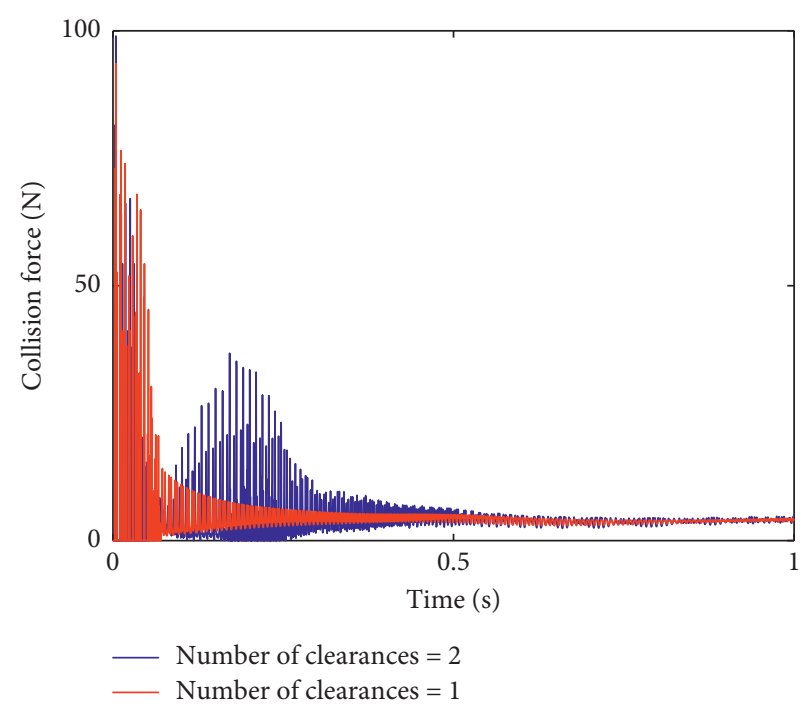

FIGURE 12: Collision force with different numbers of clearances.

and its peak value is $82.93 \mathrm{~m} / \mathrm{s}^{2}$; when the clearance value of the seven-bar mechanism is $0.05 \mathrm{~mm}$, the peak value of the output response curve of the slider acceleration appears at $0.0042 \mathrm{~s}$ and its peak value is $94.8 \mathrm{~m} / \mathrm{s}^{2}$; when the clearance value of the seven-bar mechanism is $0.07 \mathrm{~mm}$, the peak value of the output response curve of the slider acceleration appears at $0.0049 \mathrm{~s}$ and its peak value is $115.6 \mathrm{~m} / \mathrm{s}^{2}$; and when the clearance value of the seven-bar mechanism is $0.09 \mathrm{~mm}$, the peak value of the output response curve of the slider acceleration appears at $0.0055 \mathrm{~s}$ and its peak value is $137 \mathrm{~m} / \mathrm{s}^{2}$. Therefore, when the clearance value increases, the peak value of the acceleration output response curve of the slider increases and the vibration intensifies. According to the collision force contrast figure in Figure 17, when the clearance value is $0.03 \mathrm{~mm}$, the peak value appears at $0.0023 \mathrm{~s}$ and the maximum of the collision force is $65.96 \mathrm{~N}$; when the clearance 


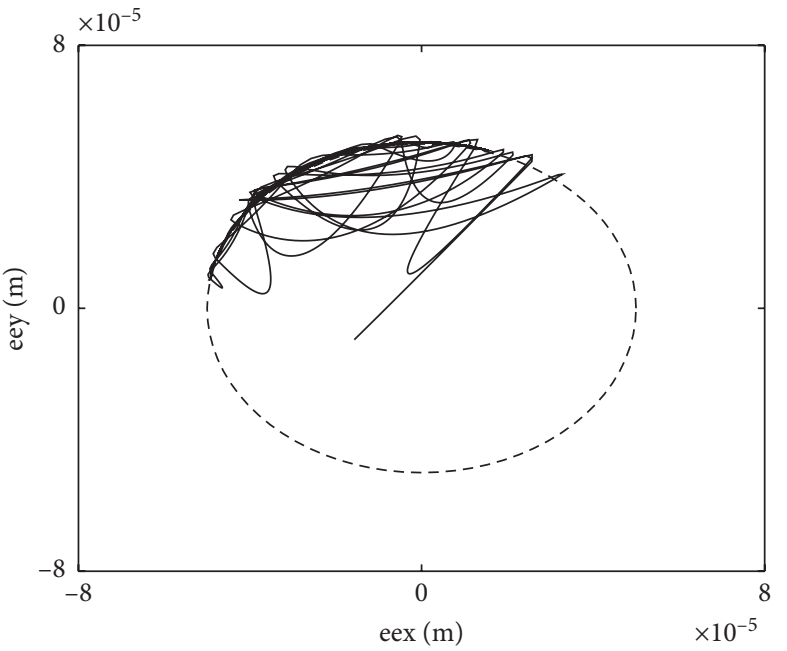

- Number of clearances $=1$

(a)

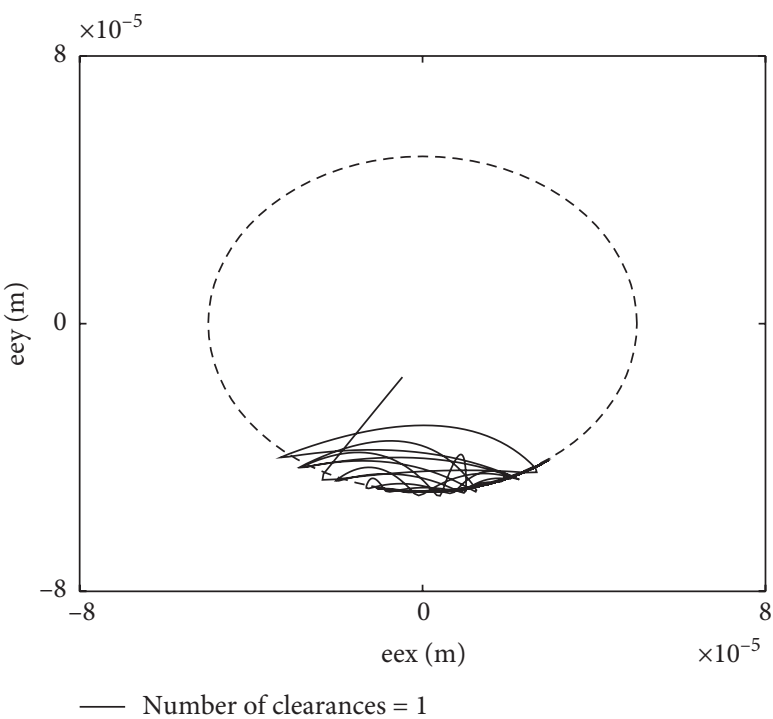

(c)

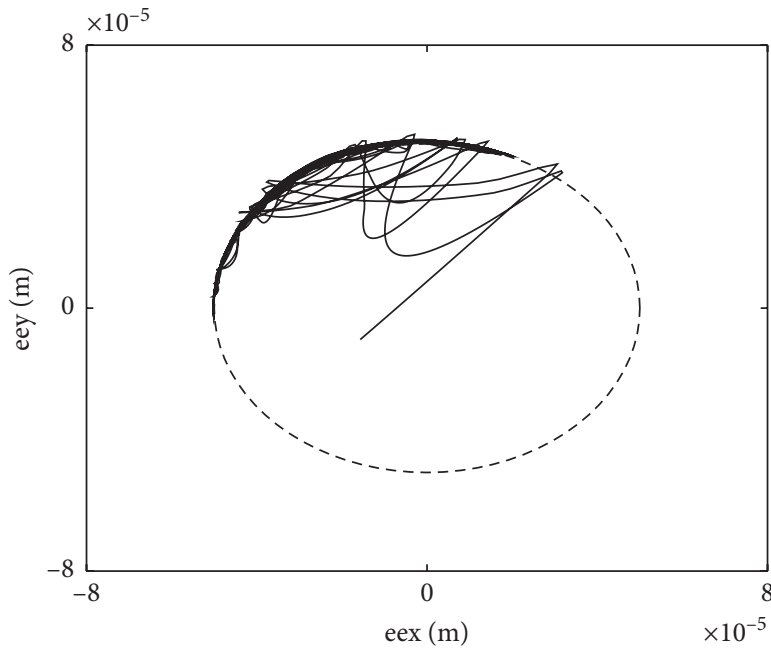

- Number of clearances $=2$

(b)

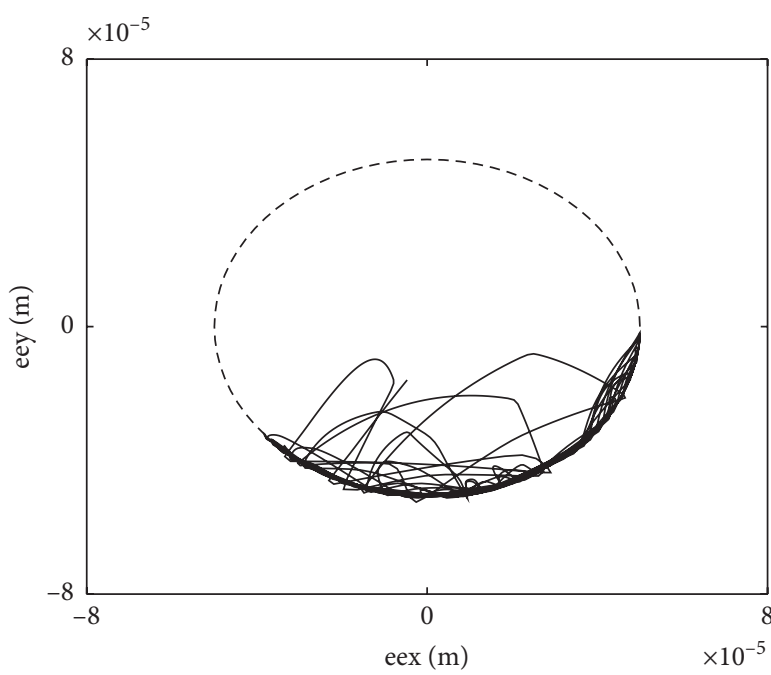

- Number of clearances $=2$

(d)

FiguRE 13: Shaft center motion trajectory at (a) clearance A when the number of clearances is 1, (b) clearance A when the number of clearances is 2 , (c) clearance $C$ when the number of clearances is 1 , and (d) clearance $C$ when the number of clearances is 2 .

value is $0.05 \mathrm{~mm}$, the peak value appears at $0.0042 \mathrm{~s}$ and the maximum of the collision force is $93.56 \mathrm{~N}$; when the clearance value is $0.07 \mathrm{~mm}$, the peak value appears at $0.0049 \mathrm{~s}$ and the maximum of the collision force is $108.6 \mathrm{~N}$; and when the clearance value is $0.09 \mathrm{~mm}$, the peak value appears at $0.0055 \mathrm{~s}$ and the maximum of the collision force is $125.26 \mathrm{~N}$. Therefore, when the clearance value increases, the maximum of impact force increases, which is consistent with the result of acceleration shown in Figure 16. According to the shaft center motion trajectory figure in Figure 18, it can be seen that the clearance value increases, the collision range increases, and the trajectory of the shaft center becomes more chaotic.

4.5. Influence of Different Driving Velocities on the Dynamic Characteristics. In this section, the influence of driving velocities on the dynamic characteristics of the seven-bar mechanism is discussed. The clearance value is set to $0.05 \mathrm{~mm}$, and the corresponding speeds of the two cranks are set to $\omega_{2}=-2 \pi(\mathrm{rad} / \mathrm{s}), \omega_{7}=2 \pi(\mathrm{rad} / \mathrm{s})$ and $\omega_{2}=-5 \pi$ $(\mathrm{rad} / \mathrm{s}), \omega_{7}=5 \pi(\mathrm{rad} / \mathrm{s})$. The displacement, velocity, acceleration, collision force curve at clearance, and shaft center trajectory of the seven-bar mechanism with different driving velocities are obtained.

As shown in Figures 19-21, when the corresponding speeds of the two cranks are set to $\omega_{2}=-2 \pi$ $(\mathrm{rad} / \mathrm{s}), \omega_{7}=2 \pi(\mathrm{rad} / \mathrm{s})$, the fluctuation amplitude of the actual displacement output curve of the slider is smaller than that of the ideal output curve, but there is an obvious lag phenomenon. Followed by the speed, the actual speed output curve of the slider has obvious zigzag fluctuation with respect to the ideal output curve, and the actual acceleration 


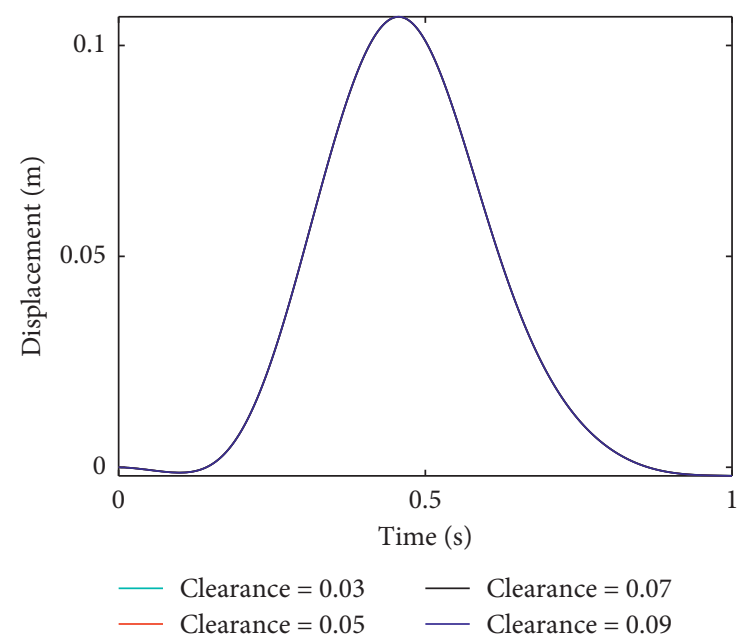

FIGURE 14: Displacement of the slider with different clearance values.

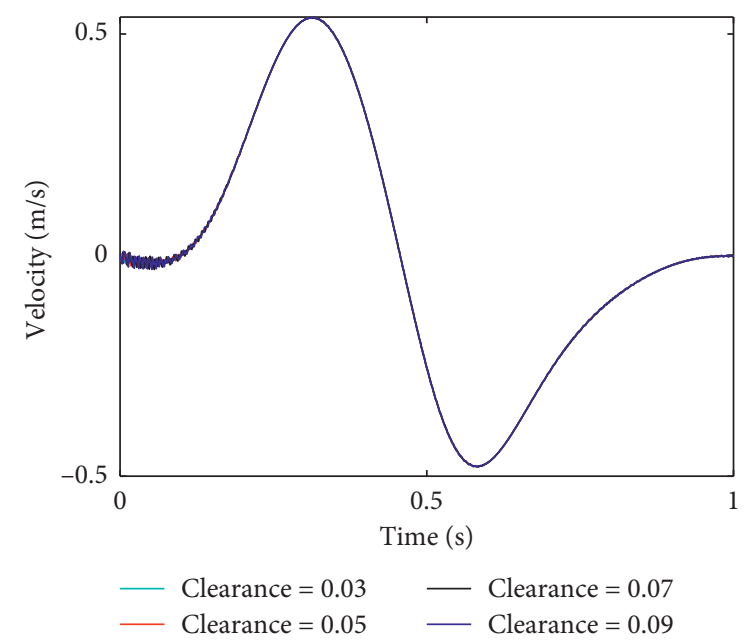

FIGURE 15: Velocity of the slider with different clearance values.

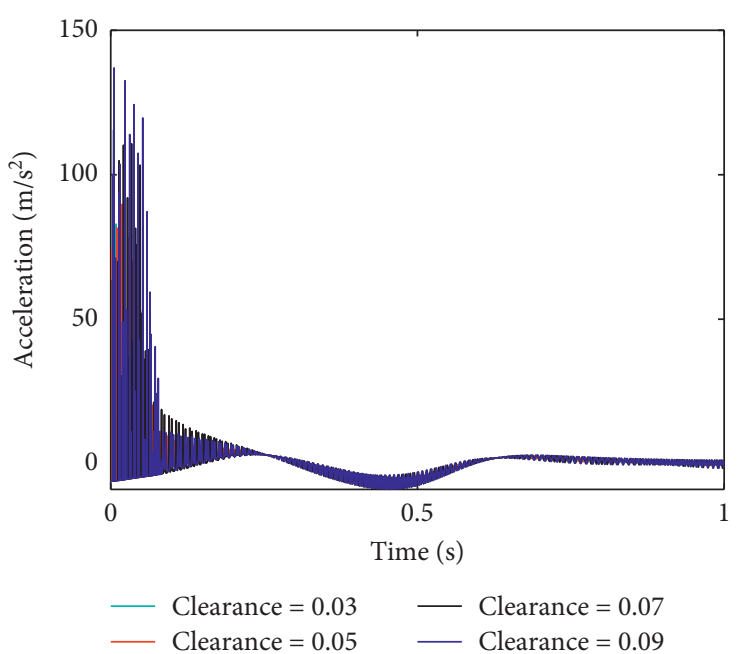

Figure 16: Acceleration of the slider with different clearance values.

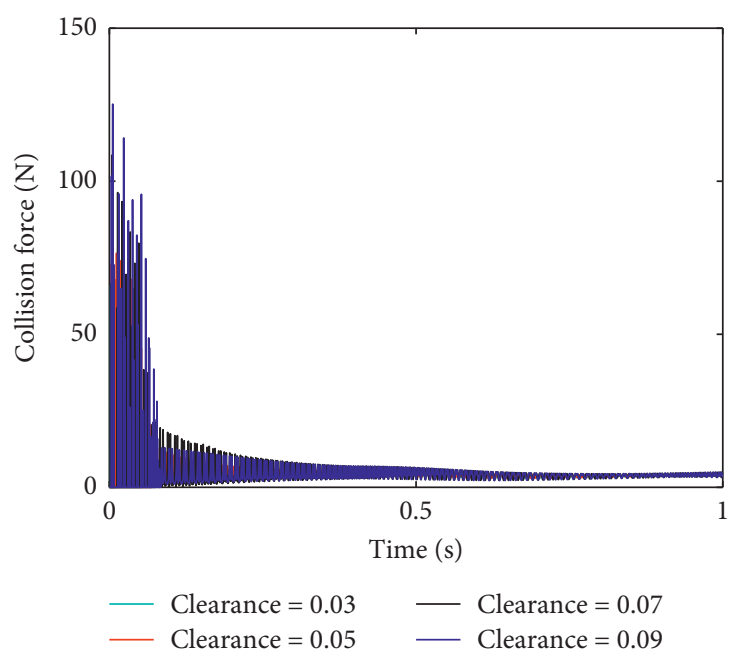

FIgURE 17: Collision force with different clearance values.

output curve of the slider has the largest fluctuation amplitude with respect to the ideal output curve; when the corresponding speeds of the two cranks are set to $\omega_{2}=-5 \pi(\mathrm{rad} / \mathrm{s}), \omega_{7}=5 \pi(\mathrm{rad} / \mathrm{s})$, the actual displacement output curve of the slider fluctuates greatly with respect to the ideal output curve, and there is an obvious lag phenomenon. Followed by the speed, the actual speed output curve of the slider changes with respect to the peak value of the ideal output curve, from $1.34 \mathrm{~m} / \mathrm{s}$ to $1.48 \mathrm{~m} / \mathrm{s}$, and the actual acceleration output curve of the slider fluctuates most with respect to the ideal output curve, and the peak value of the line changed from $24.63 \mathrm{~m} / \mathrm{s}$ to $349.9 \mathrm{~m} / \mathrm{s}^{2}$; when the driving speed increases from $\omega_{2}=-2 \pi(\mathrm{rad} / \mathrm{s}), \omega_{7}=2 \pi(\mathrm{rad} / \mathrm{s})$ to $\omega_{2}=-5 \pi(\mathrm{rad} / \mathrm{s}), \omega_{7}=5 \pi(\mathrm{rad} / \mathrm{s})$, the peak velocity of the slider increases from $0.5376 \mathrm{~m} / \mathrm{s}$ to $1.48 \mathrm{~m} / \mathrm{s}$ and the peak acceleration increases from $311 \mathrm{~m} / \mathrm{s}^{2}$ to $349.4 \mathrm{~m} / \mathrm{s}^{2}$. As shown in Figure 22, with the increase of driving velocity, the collision trend at clearance $\mathrm{A}$ and clearance $\mathrm{C}$ is more obvious, the collision amplitude is more intense, the collision force generated by the collision also increases, the peak value at clearance $\mathrm{A}$ increases from $98.97 \mathrm{~N}$ to $102.8 \mathrm{~N}$, and the peak value at clearance $\mathrm{C}$ increases from $55.64 \mathrm{~N}$ to 74.91 N. As shown in Figure 23, with the increase of driving velocity, the collision range increases and the trajectory of the shaft center becomes more chaotic, which is consistent with the acceleration and collision force results shown in Figures 21 and 22 .

\section{Effects of Main Parameters on Chaotic Motion in the Hybrid Driven Seven-Bar Mechanism with Clearances}

At present, the Poincare map and phase trajectory map are widely used in the study of chaos in nonlinear dynamical systems. By observing the intersection of the phase trajectory and Poincare mapping section, we can know the motion characteristics of the dynamic system. A point or a few discrete points on the Poincare map, closed curve, and dense 


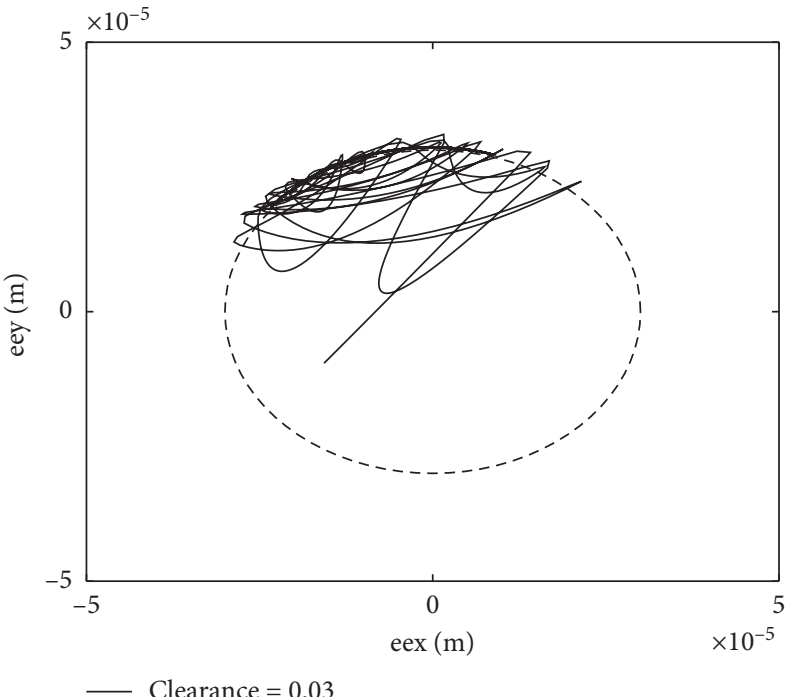

(a)

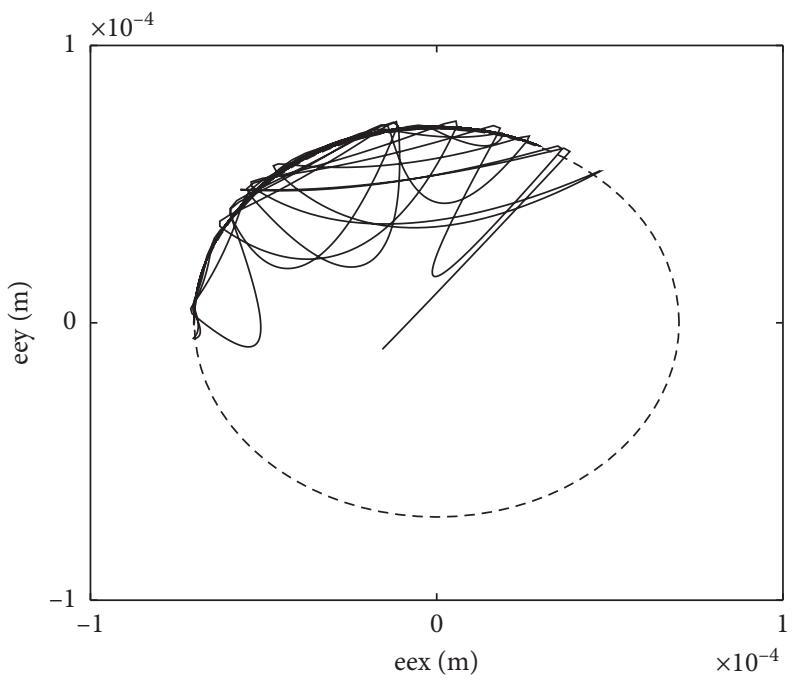

- Clearance $=0.07$

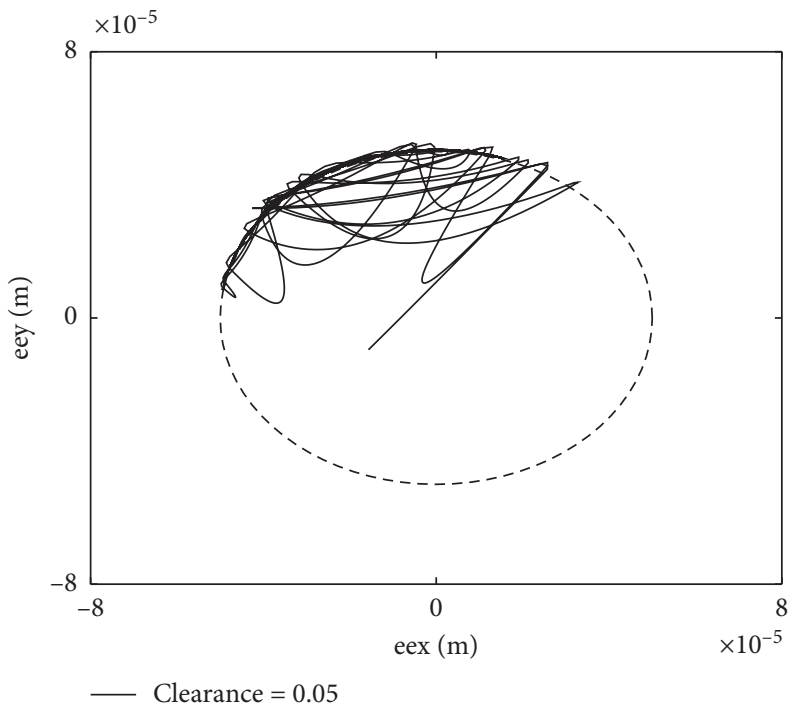

(b)

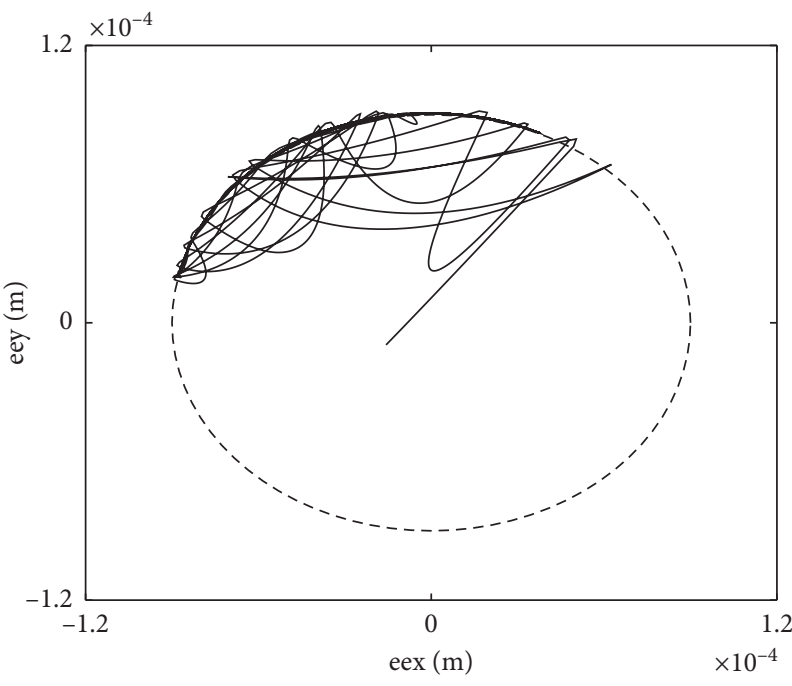

(d)

FIgURE 18: Shaft center motion trajectory. (a) Clearance $=0.03 \mathrm{~mm}$. (b) Clearance $=0.05 \mathrm{~mm}$. (c) Clearance $=0.07 \mathrm{~mm}$.

(d) Clearance $=0.09 \mathrm{~mm}$.

points with the typed structure in a certain region represent the periodic motion, quasiperiodic motion, and chaotic motion, respectively.

In this paper, in order to better study the dynamic characteristics of the hybrid seven-bar mechanism with clearance, different clearance values and different driving speeds are used to study the mechanism in detail.

\subsection{Influence of Different Clearance Values on Chaotic} Motion. In this paper, the corresponding speeds of the two cranks are set to $\omega_{2}=-2 \pi(\mathrm{rad} / \mathrm{s}), \omega_{7}=2 \pi(\mathrm{rad} / \mathrm{s})$. And the influence of different clearance values on the chaotic motion of the mechanism is studied by using the phase trajectory map and Poincare map of different clearance values in the $X$ direction.
According to Figures 24 and 25, when the clearance value is $0.01 \mathrm{~mm}$, whether it is at clearance $A$ or clearance $C$, the point on the Poincare map is a closed circle, which shows that the mechanism is in a quasiperiodic state at this time. When the clearance value is $0.8 \mathrm{~mm}$, whether it is at clearance A or clearance $\mathrm{C}$, the points on the Poincare map are disordered and irregular, which shows that the mechanism is in a chaotic state at this time.

Because bifurcation diagrams can better understand the dynamic characteristics of the system with clearance values, this paper chooses the range of the clearance value to be [0.01 $\mathrm{mm}, 1 \mathrm{~mm}]$ to study the bifurcation of the dynamic characteristics, as shown in Figure 26. As shown in Figure 26, when the clearance value increases, the mechanism will change from the periodic motion to the chaotic 


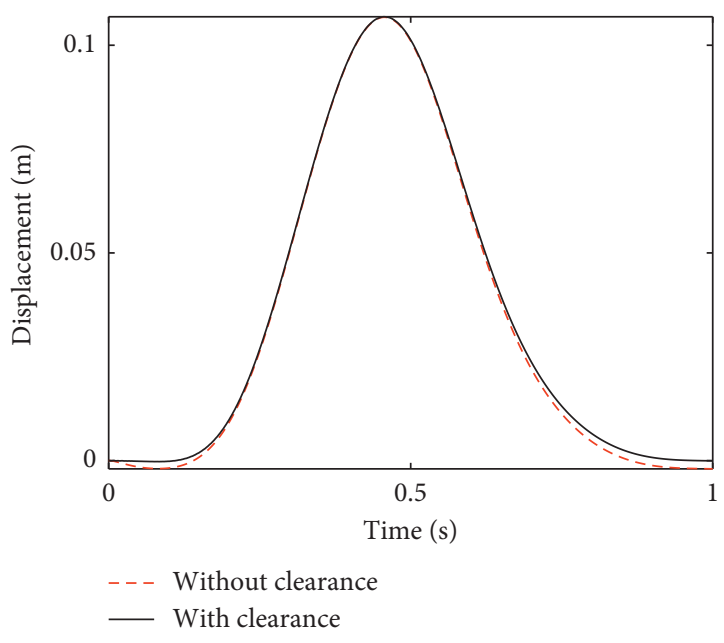

(a)

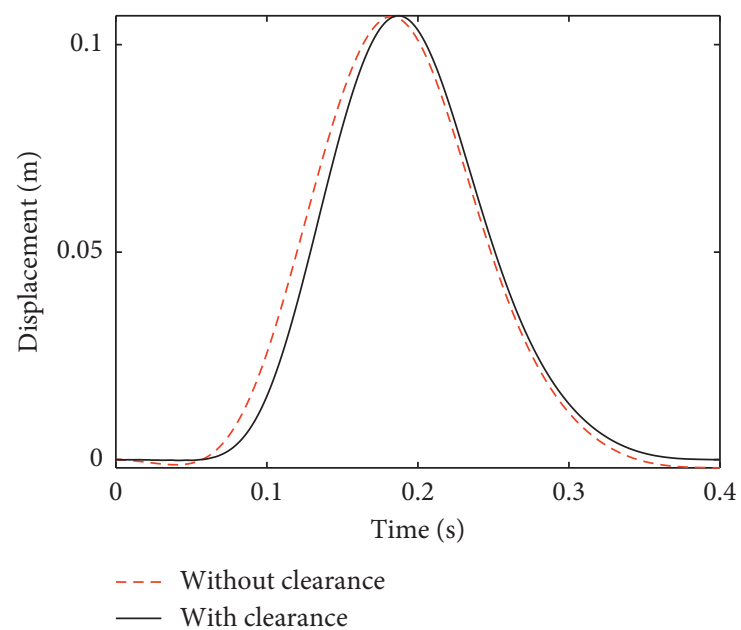

(b)

FIGURE 19: Displacement of the slider. (a) $\omega_{2}=-2 \pi(\mathrm{rad} / \mathrm{s}), \omega_{7}=2 \pi(\mathrm{rad} / \mathrm{s})$. (b) $\omega_{2}=-5 \pi(\mathrm{rad} / \mathrm{s}), \omega_{7}=5 \pi(\mathrm{rad} / \mathrm{s})$.

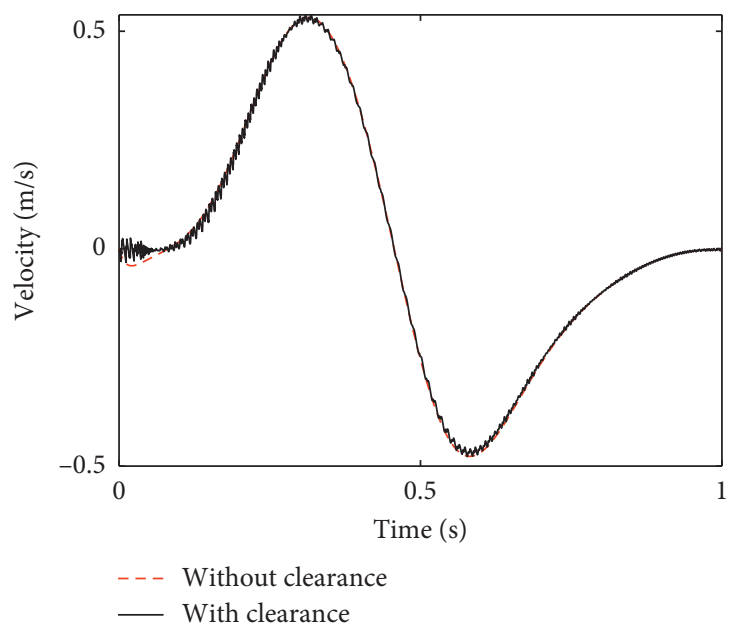

(a)

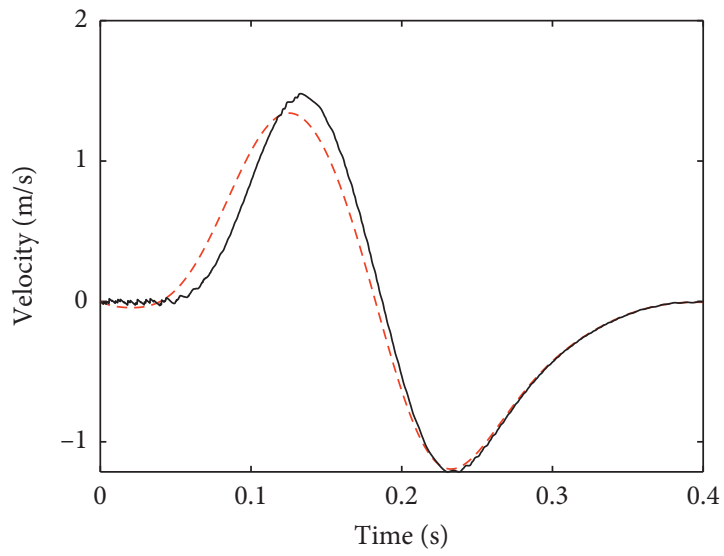

- - - Without clearance

_ With clearance

FIGURE 20: Velocity of the slider. (a) $\omega_{2}=-2 \pi(\mathrm{rad} / \mathrm{s}), \omega_{7}=2 \pi(\mathrm{rad} / \mathrm{s})$. (b) $\omega_{2}=-5 \pi(\mathrm{rad} / \mathrm{s}), \omega_{7}=5 \pi(\mathrm{rad} / \mathrm{s})$.

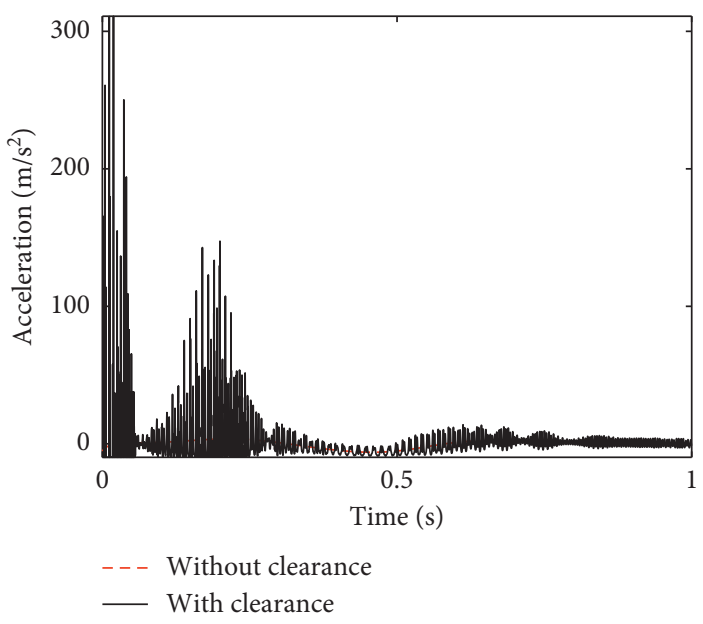

(a)

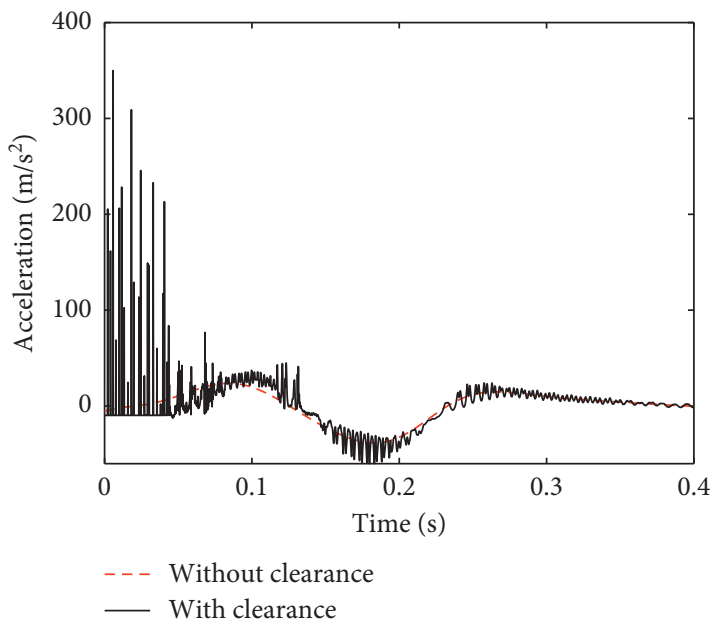

(b)

Figure 21: Acceleration of the slider. (a) $\omega_{2}=-2 \pi(\mathrm{rad} / \mathrm{s}), \omega_{7}=2 \pi(\mathrm{rad} / \mathrm{s})$. (b) $\omega_{2}=-5 \pi(\mathrm{rad} / \mathrm{s}), \omega_{7}=5 \pi(\mathrm{rad} / \mathrm{s})$. 


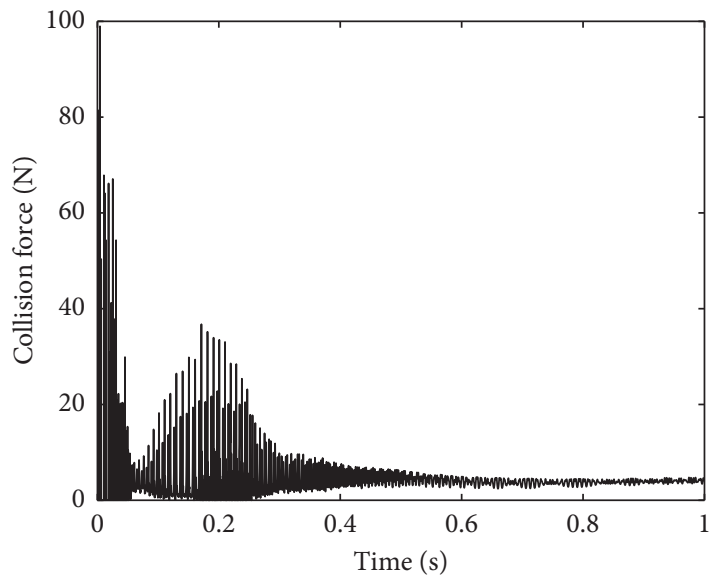

- Clearance A

(a)

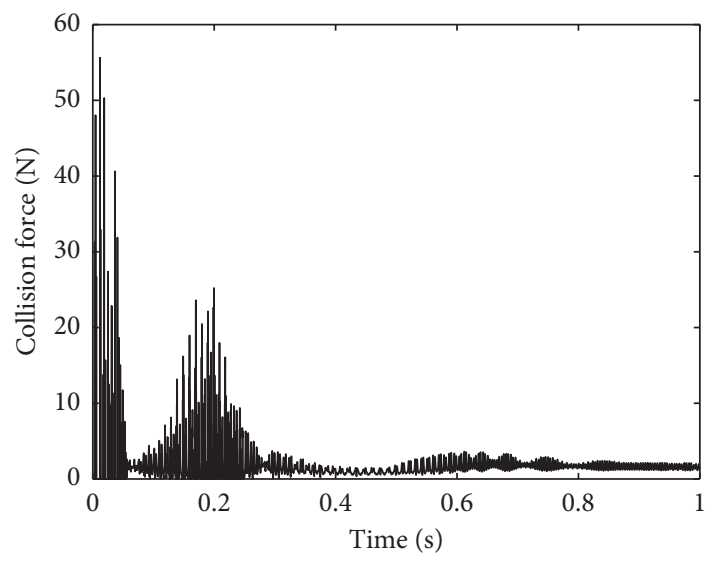

- Clearance C

(c)

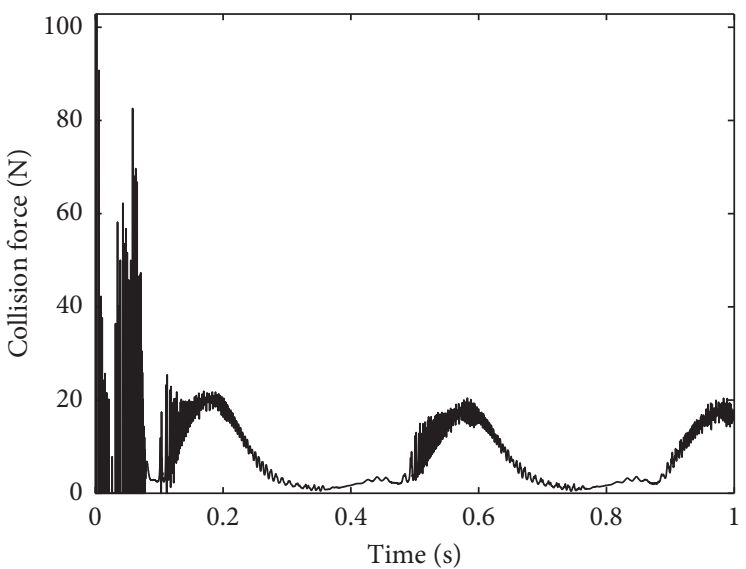

- Clearance A

(b)

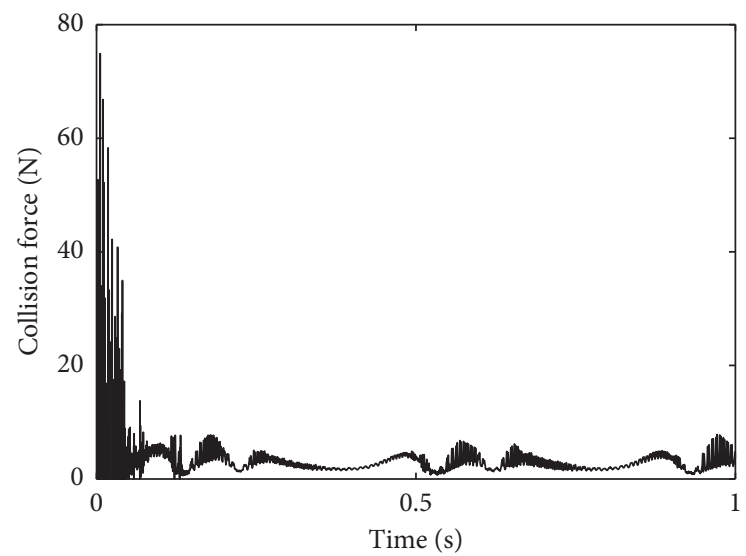

- Clearance C

(d)

Figure 22: Collision force. (a) $\omega_{2}=-2 \pi(\mathrm{rad} / \mathrm{s}), \omega_{7}=2 \pi(\mathrm{rad} / \mathrm{s})$. $\omega_{2}=-2 \pi(\mathrm{rad} / \mathrm{s}), \omega_{7}=2 \pi(\mathrm{rad} / \mathrm{s}) .(\mathrm{d}) \omega_{2}=-5 \pi(\mathrm{rad} / \mathrm{s}), \omega_{7}=5 \pi(\mathrm{rad} / \mathrm{s})$.

(b) $\quad \omega_{2}=-5 \pi(\mathrm{rad} / \mathrm{s}), \omega_{7}=5 \pi(\mathrm{rad} / \mathrm{s})$.

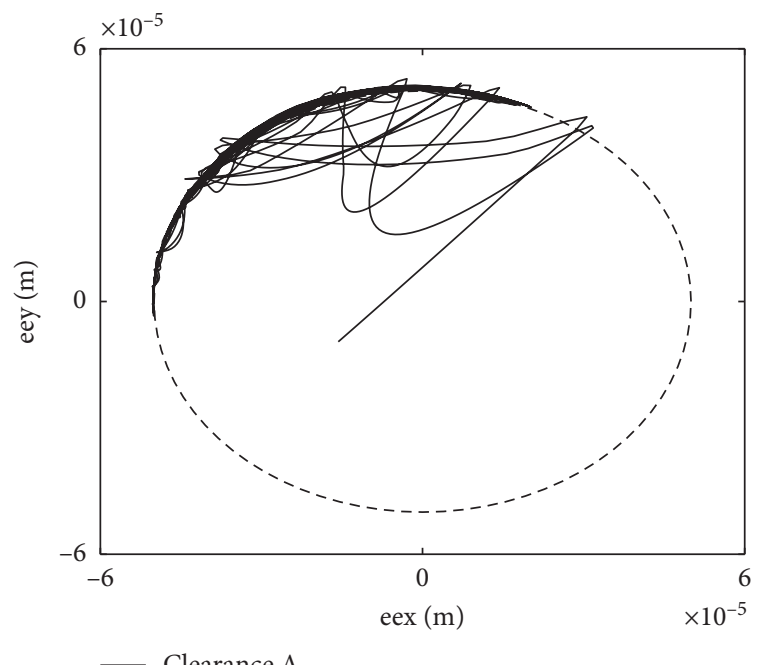

(a)

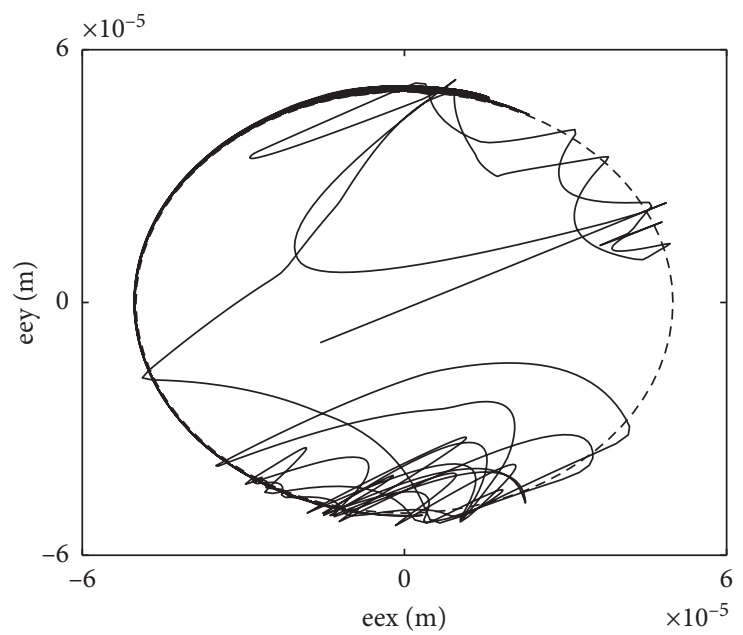

(b)

FIgure 23: Continued. 


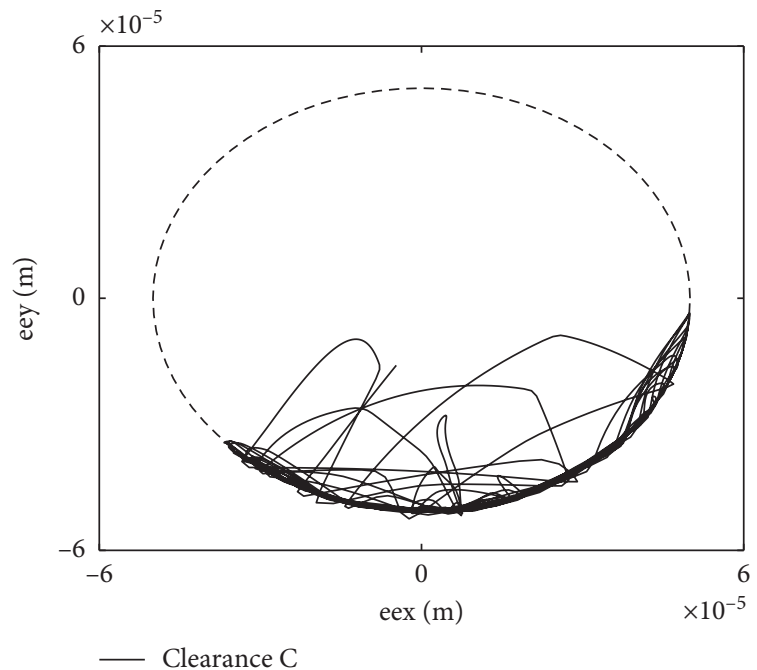

(c)

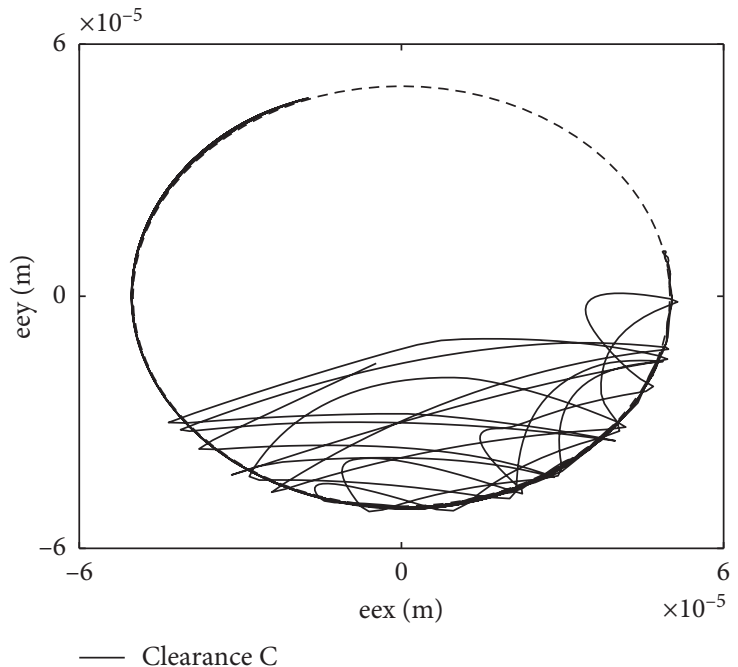

(d)

Figure 23: Shaft center motion trajectory. (a) $\omega_{2}=-2 \pi(\mathrm{rad} / \mathrm{s}), \omega_{7}=2 \pi(\mathrm{rad} / \mathrm{s}) . \quad$ (b) $\omega_{2}=-5 \pi(\mathrm{rad} / \mathrm{s}), \omega_{7}=5 \pi(\mathrm{rad} / \mathrm{s})$. (c) $\omega_{2}=-2 \pi(\mathrm{rad} / \mathrm{s}), \omega_{7}=2 \pi(\mathrm{rad} / \mathrm{s})$. (d) $\omega_{2}=-5 \pi(\mathrm{rad} / \mathrm{s}), \omega_{7}=5 \pi(\mathrm{rad} / \mathrm{s})$.

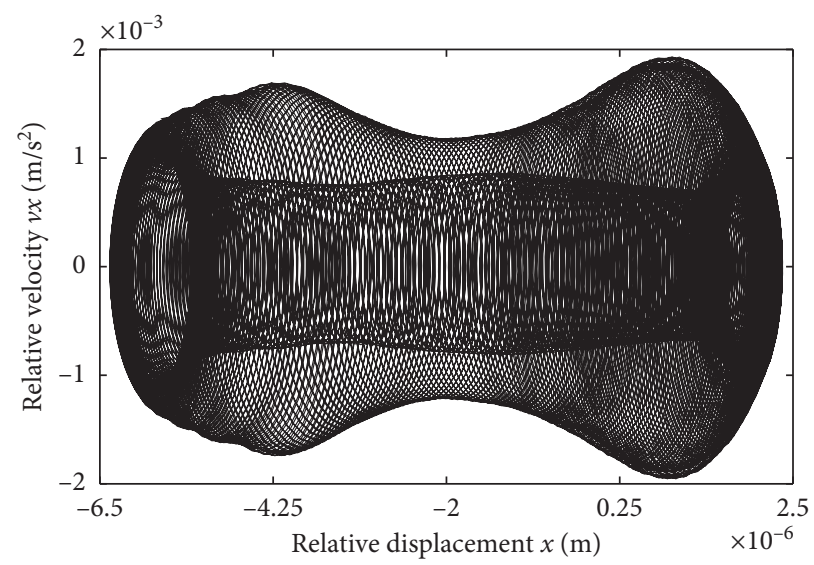

(a)

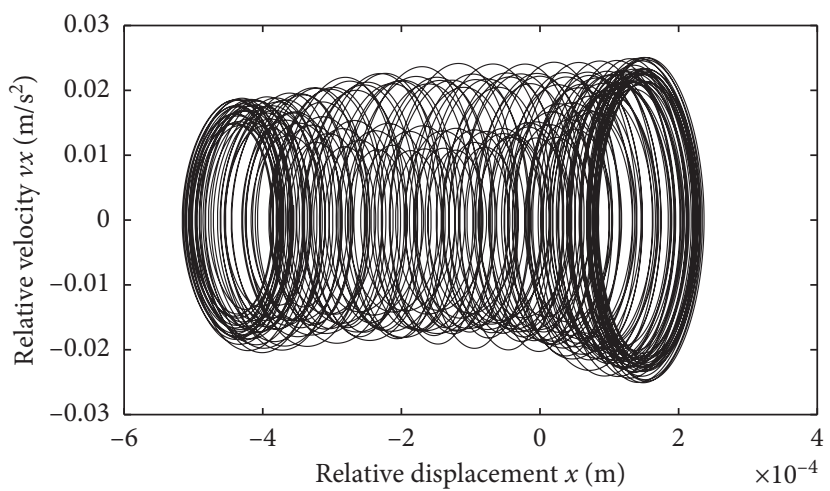

(c)

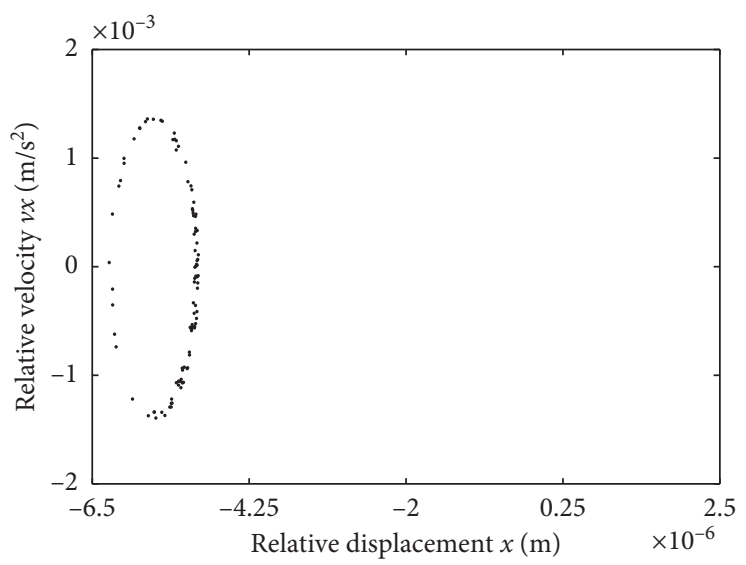

(b)

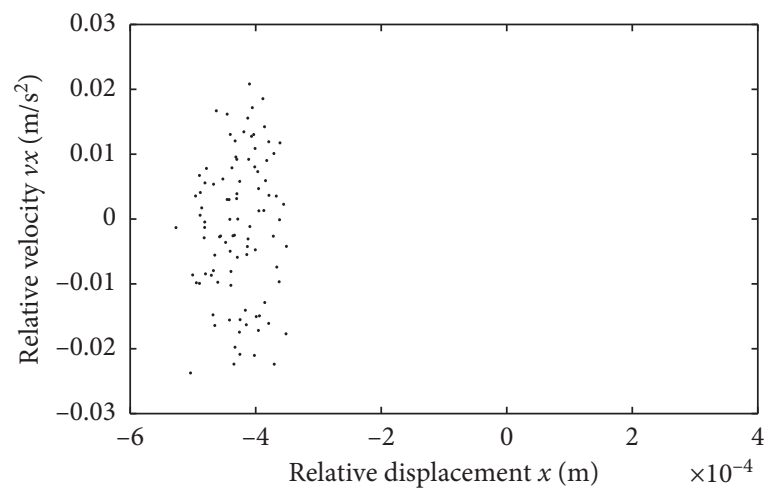

(d)

Figure 24: Phase trajectories and Poincare maps of $X$-direction clearances with different clearance values at clearance A. (a) Phase trace diagram at clearance A when the clearance value is $0.01 \mathrm{~mm}$. (b) Poincare map at clearance A when the clearance value is $0.01 \mathrm{~mm}$. (c) Phase trace diagram at clearance A when the clearance value is $0.8 \mathrm{~mm}$. (d) Poincare map at clearance A when the clearance value is $0.8 \mathrm{~mm}$. 


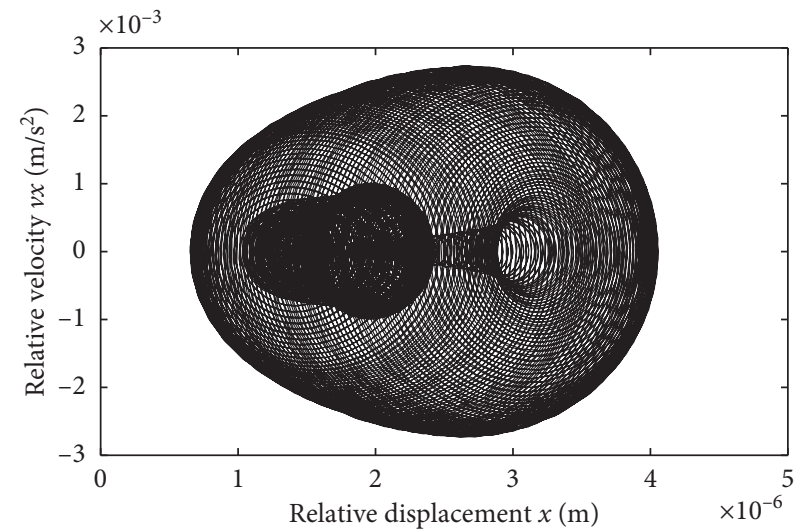

(a)

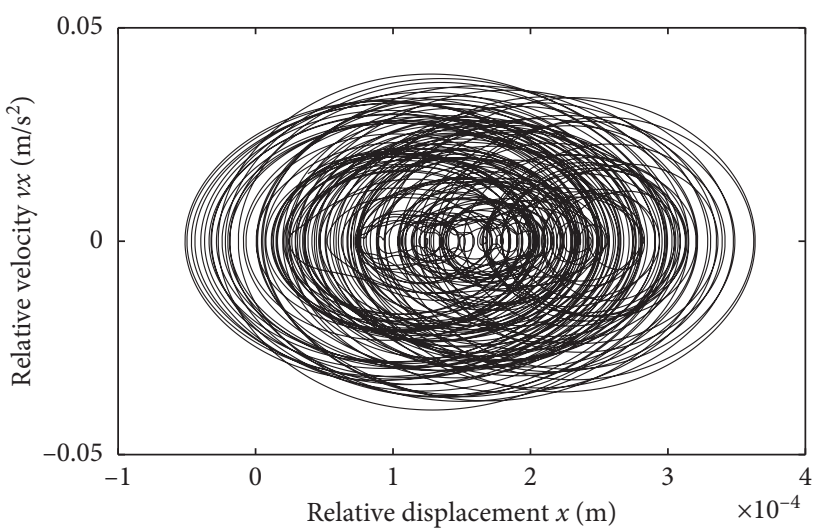

(c)

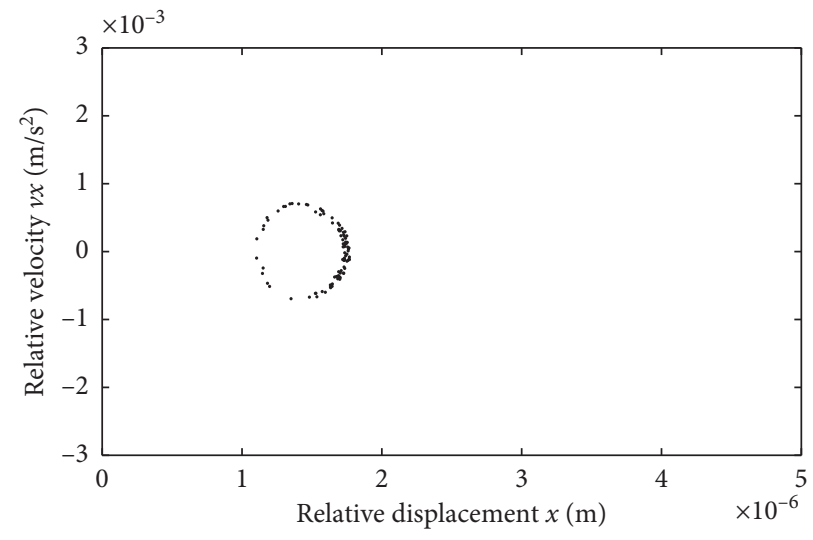

(b)

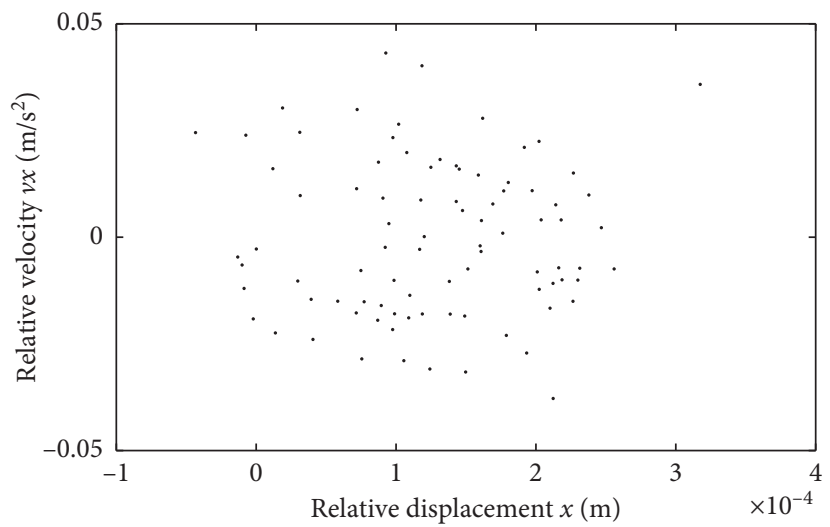

(d)

Figure 25: Phase trajectories and Poincare maps of $X$-direction clearances with different clearance values at clearance C. (a) Phase trace diagram at clearance $C$ when the clearance value is $0.01 \mathrm{~mm}$. (b) Poincare map at clearance $C$ when the clearance value is $0.01 \mathrm{~mm}$. (c) Phase trace diagram at clearance $\mathrm{C}$ when the clearance value is $0.8 \mathrm{~mm}$. (d) Poincare map at clearance $\mathrm{C}$ when the clearance value is $0.8 \mathrm{~mm}$.

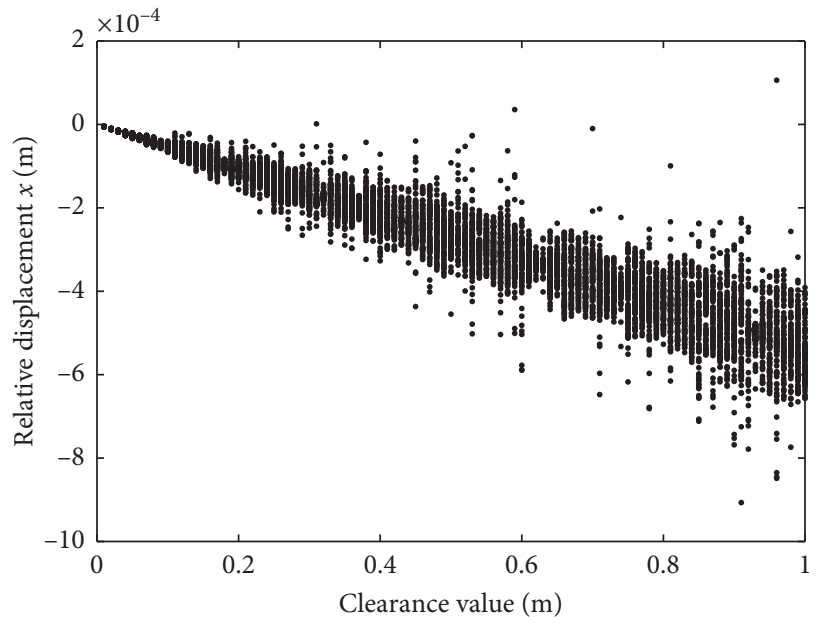

(a)

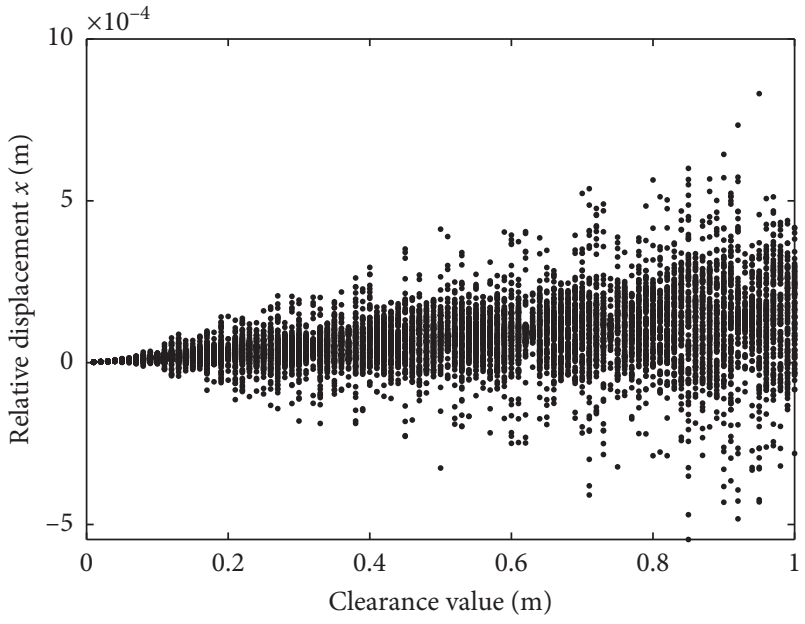

(b)

FIGURE 26: Variable clearance bifurcation diagram of the seven-bar hybrid drive at (a) clearance A and (b) clearance C.

motion. Therefore, clearance value has an important influence on the motion state of the seven-bar hybrid drive with clearance.
5.2. Effects of Different Driving Velocities on Chaotic Motion. In this paper, the clearance value is set to $0.05 \mathrm{~mm}$. And the effect of different driving velocities on the chaotic motion of 


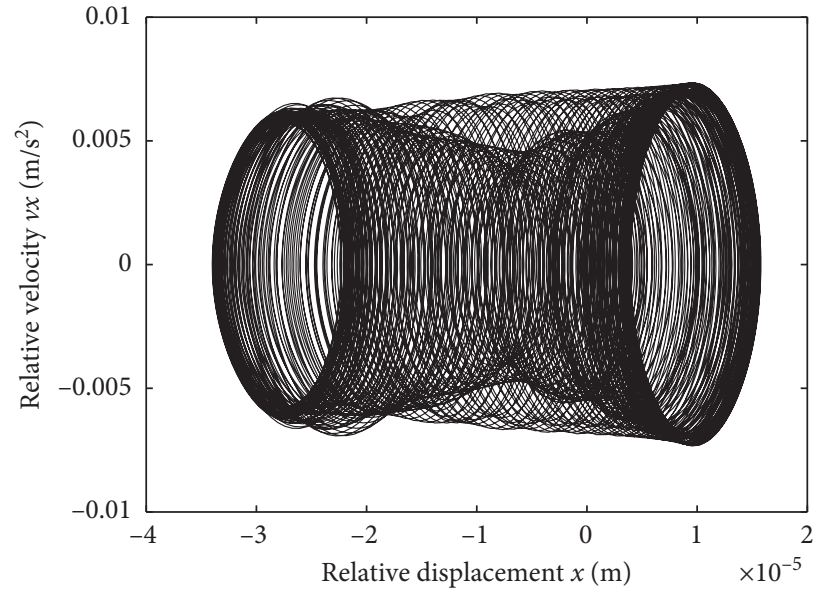

(a)

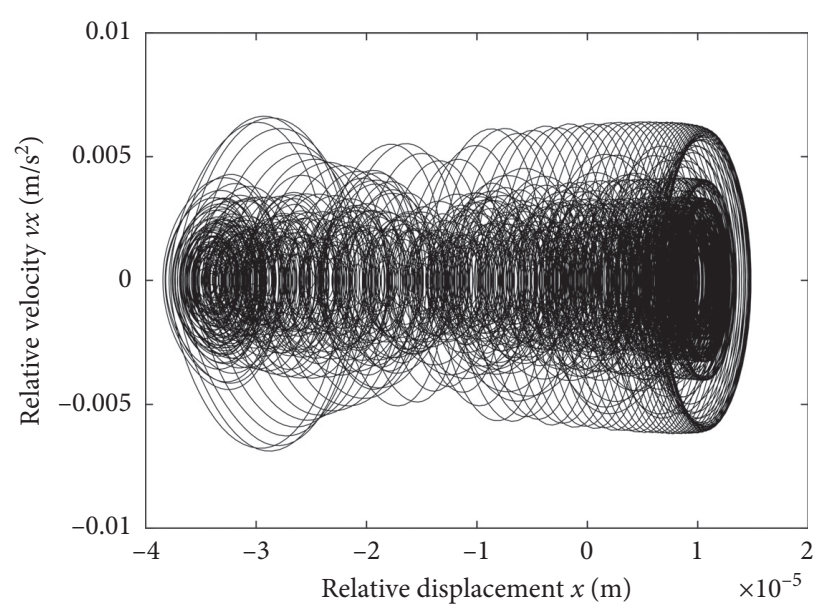

(c)

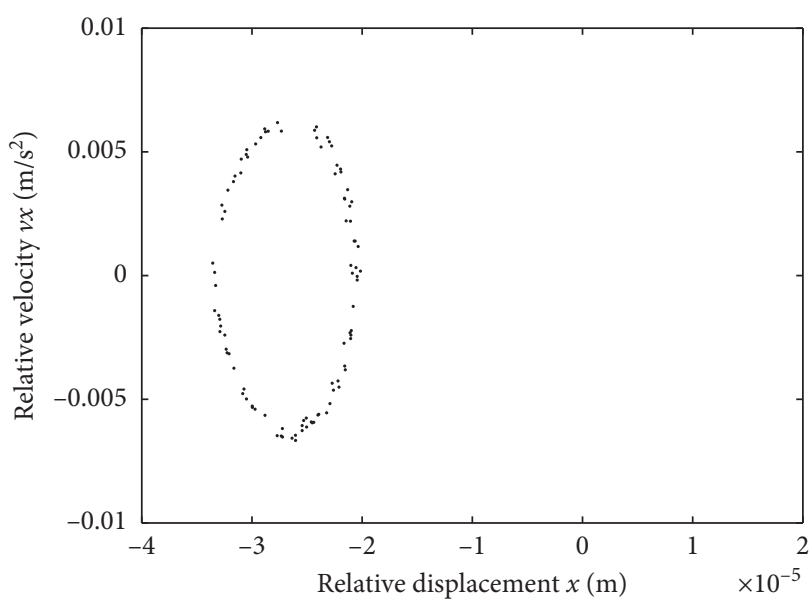

(b)

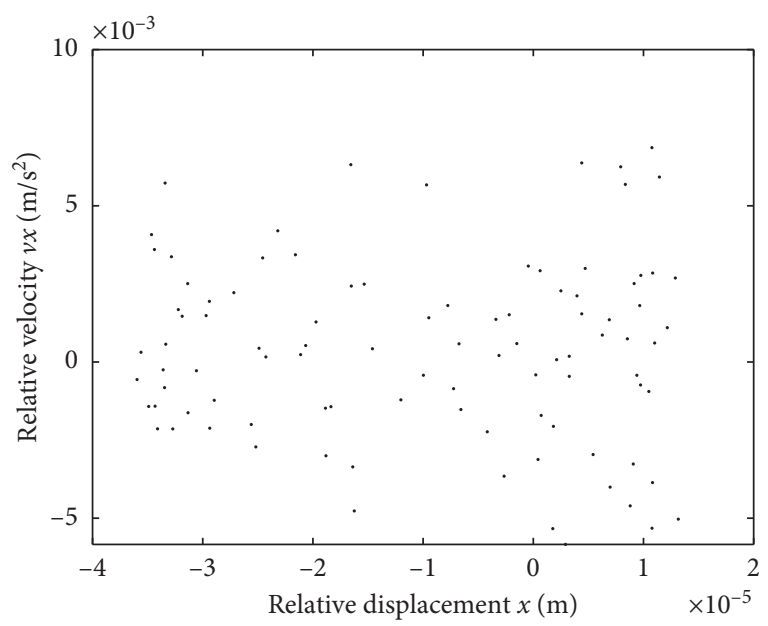

(d)

Figure 27: Phase trajectories and Poincare maps of $X$-direction clearances with different clearance values at clearance A. (a) Phase trace diagram at clearance $A$ when the driving velocities are $\omega_{2}=-2 \pi(\mathrm{rad} / \mathrm{s}), \omega_{7}=2 \pi(\mathrm{rad} / \mathrm{s})$. (b) Poincare map at clearance A when the driving velocities are $\omega_{2}=-2 \pi(\mathrm{rad} / \mathrm{s}), \omega_{7}=2 \pi(\mathrm{rad} / \mathrm{s})$. (c) Phase trace diagram at clearance A when the driving velocities are $\omega_{2}=-2.9 \pi(\mathrm{rad} / \mathrm{s}), \omega_{7}=2.9 \pi(\mathrm{rad} / \mathrm{s})$. (d) Poincare map at clearance A when the driving velocities are $\omega_{2}=-2.9 \pi(\mathrm{rad} / \mathrm{s}), \omega_{7}=2.9 \pi(\mathrm{rad} / \mathrm{s})$.

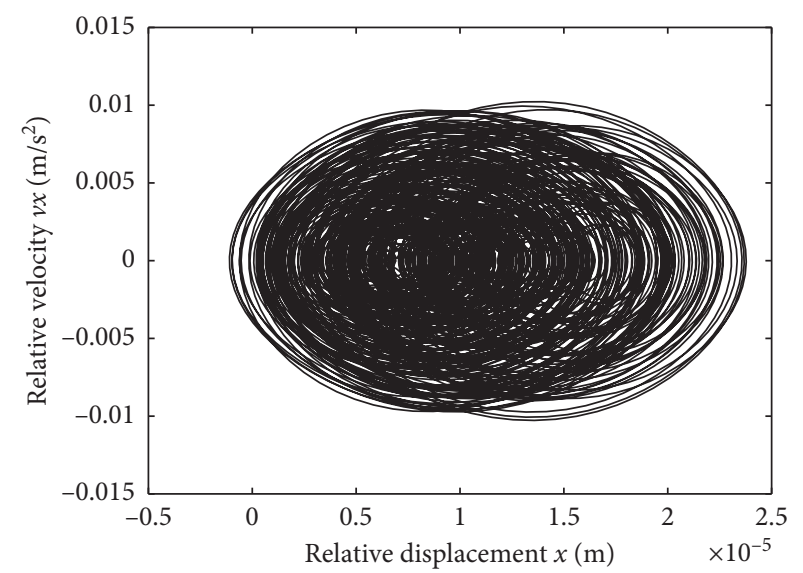

(a)

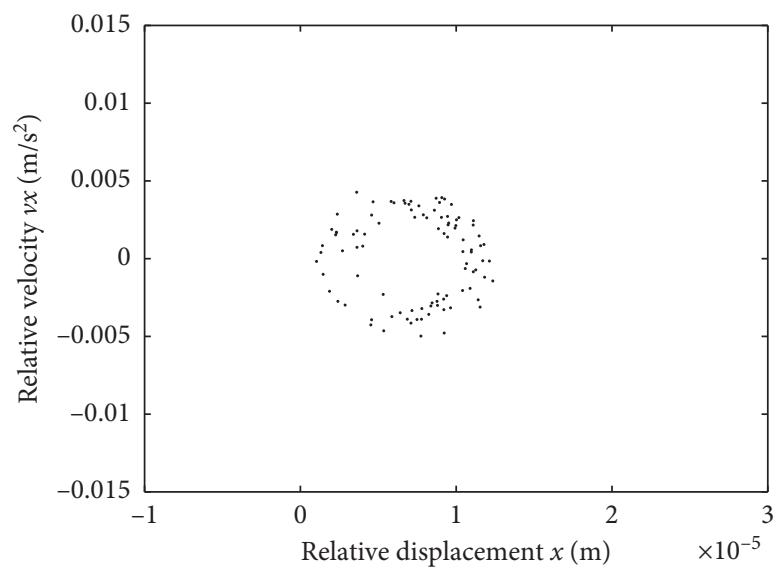

(b)

Figure 28: Continued. 


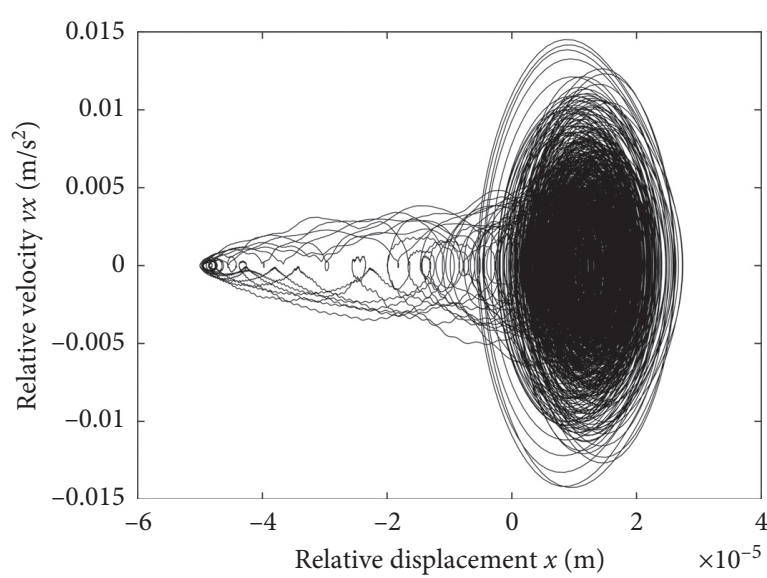

(c)

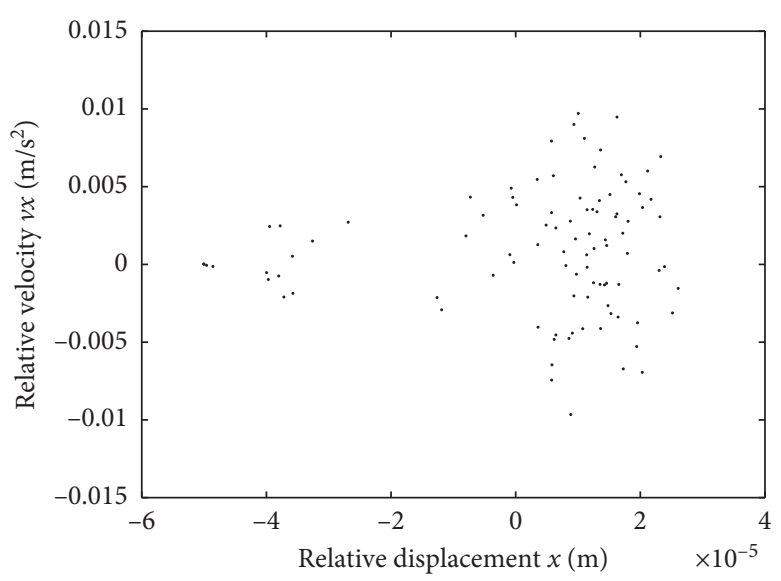

(d)

Figure 28: Phase trajectories and Poincare maps of $X$-direction clearances with different clearance values at clearance C. (a) Phase trace diagram at clearance $C$ when the driving velocities are $\omega_{2}=-2 \pi(\mathrm{rad} / \mathrm{s}), \omega_{7}=2 \pi(\mathrm{rad} / \mathrm{s})$. (b) Poincare map at clearance $C$ when the driving velocities are $\omega_{2}=-2 \pi(\mathrm{rad} / \mathrm{s}), \omega_{7}=2 \pi(\mathrm{rad} / \mathrm{s})$. (c) Phase trace diagram at clearance $\mathrm{C}$ when the driving velocities are $\omega_{2}=-2.9 \pi(\mathrm{rad} / \mathrm{s}), \omega_{7}=2.9 \pi(\mathrm{rad} / \mathrm{s})$. (d) Poincare map at clearance $\mathrm{C}$ when the driving velocities are $\omega_{2}=-2.9 \pi(\mathrm{rad} / \mathrm{s}), \omega_{7}=2.9 \pi(\mathrm{rad} / \mathrm{s})$.

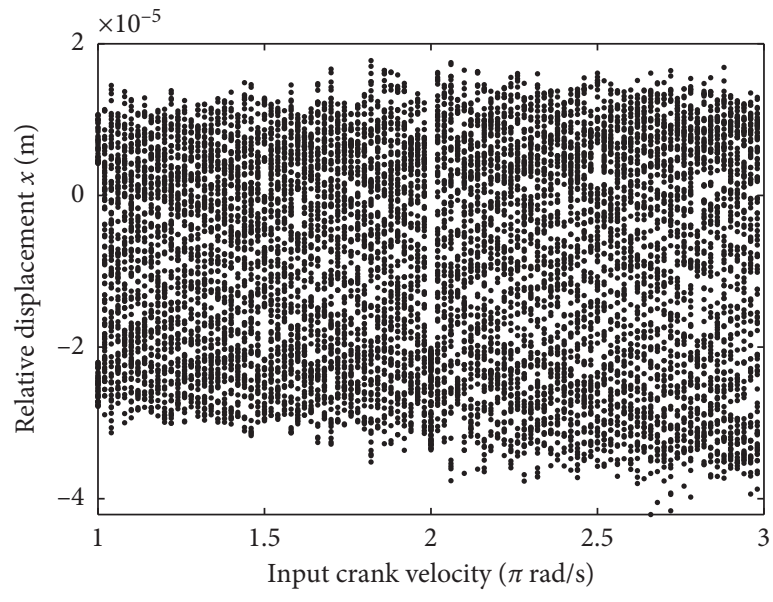

(a)

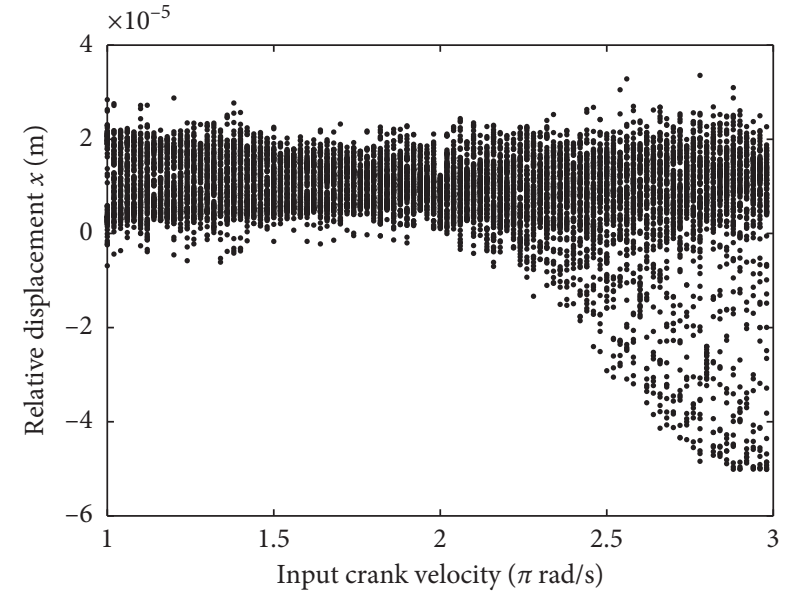

(b)

FIgUre 29: Bifurcation diagram of variable driving velocities of the seven-bar hybrid drive at (a) clearance A and (b) clearance C.

the mechanism is studied by using the phase trajectory map and Poincare map of different driving velocities in the $X$ direction.

According to Figures 27 and 28, the corresponding speeds of the two cranks are set to $\omega_{2}=-2 \pi(\mathrm{rad} /$ $\mathrm{s}), \omega_{7}=2 \pi(\mathrm{rad} / \mathrm{s})$. The Poincare mapping points at clearance $A$ are a closed circle, which indicates that the mechanism is in a quasiperiodic state, and the Poincare mapping points at clearance $\mathrm{C}$ are disordered and irregular, which shows that the mechanism is in a chaotic state at this time. When the driving velocity is $\omega_{2}=-2.9 \pi(\mathrm{rad} / \mathrm{s}), \omega_{7}=2.9 \pi(\mathrm{rad} / \mathrm{s})$, the Poincare map at clearance $\mathrm{A}$ or clearance $\mathrm{C}$ is also disordered and irregular, which shows that the mechanism is in a chaotic state at this time.
Because bifurcation diagrams can better understand the dynamic characteristics of the system with clearance values, this paper chooses the range of the driving velocity interval as $[1 \pi \mathrm{rad} / \mathrm{s}, 3 \pi \mathrm{rad} / \mathrm{s}]$ to study the bifurcation of dynamic characteristics, as shown in Figure 29 (in which the abscissa represents the clearance size and the longitudinal coordinate represents the relative displacement of the axle bearing in the $X$ direction). Figure 29 shows that although the mechanism has been chaotic, when the driving speeds increase, the chaos phenomenon has little effect on clearance $\mathrm{A}$, but it becomes more and more obvious at clearance $\mathrm{C}$, so the driving speed has an important influence on the motion state of the seven-bar hybrid drive with double clearances. 


\section{Conclusions}

The dynamic modeling, response, and chaos analysis of the 2-DOF hybrid mechanism with revolute clearances is investigated. A mathematical model of the seven-link mechanism driven by double revolute clearances is established in this paper. By changing the number, position, clearance value, and driving velocities, the displacement, velocity, and acceleration of the slider, the collision force at clearance, and the trajectory of the shaft center line are carried out. The dynamic characteristics of the mechanism are studied, and the nonlinear dynamic characteristics of the mechanism at the clearance are analyzed by different clearance values and driving speeds. The main conclusions are as follows:

(1) A computational methodology for the dynamic modeling and analysis of the planar multilink mechanism with multiple degrees of freedom and multiple clearances is proposed, and the dynamic constraint equations of the hybrid seven-bar mechanism with clearances are deduced by the Lagrange equation.

(2) The effects of different clearance values, number of clearances, clearance positions, and driving velocities on the dynamic characteristics of the seven-bar mechanism with the clearance hybrid drive were studied. When the clearance number and clearance value increase, the number of collisions between axle and bearing decreases, but the peak acceleration and collision force of slider increases due to the increase of collision strength between axle and bearing, and when the clearance number and clearance value increase, the motion accuracy of mechanism decreases. When the clearance is at the crank, the collision force is greater and the central trajectory of the shaft is more chaotic. The closer the power source of the clearance position is, the more severe the collision between the shaft and the bearing is. At this time, the mechanism is more prone to wear and even damage in the clearance. Therefore, it can be seen that the existence of the mechanism clearance has a great influence on its dynamic characteristics and the existence of clearance will reduce the stability of the mechanism. When the driving velocity increases, the peak values of displacement, velocity, and acceleration increase continuously, the collision trend is more intense, the center track of the shaft is more chaotic, the collision force is greater, and the motion accuracy of the mechanism is reduced.

(3) The Poincare diagram, phase trajectory, and diagram bifurcation diagram with different clearance values and driving speeds are studied and analyzed. The results show that when clearance values increase, the mechanism gradually changes from the original periodic state to the chaotic state. When the driving speed increases, the motion state of the two clearances is in a chaotic state, and the chaotic phenomenon at clearance $\mathrm{C}$ becomes more and more obvious.

\section{Data Availability}

The data used to support the findings of this study are included within the article.

\section{Conflicts of Interest}

The authors declare that they have no conflicts of interest.

\section{Acknowledgments}

This research was supported by the Shandong Key Research and Development Public Welfare Program (2019GGX104011), Natural Science Foundation of Shandong Province (Grant no. ZR2017MEE066), and HeavyDuty Intelligent Manufacturing Equipment Innovation Center of Hebei Province (201904).

\section{References}

[1] E. Salahshoor, S. Ebrahimi, and Y. Zhang, "Frequency analysis of a typical planar flexible multibody system with joint clearances," Mechanism and Machine Theory, vol. 126, pp. 429-456, 2018.

[2] W. Sun, C. P. Feng, and X. F. Jiang, "Design analysis and dynamics study of a two-wing spatial flapping mechanism," Machine Tool and Hydraulic Pressure, vol. 45, no. 17, pp. 52-56, 2017.

[3] L.-X. Xu, Y.-G. Y.-H. Yang, C.-N. LiWang, and S.-Y. au, "Modeling and analysis of planar multibody systems containing deep groove ball bearing with clearance," Mechanism and Machine Theory, vol. 56, pp. 69-88, 2012.

[4] X. Wang, G. Liu, S. Ma et al., "Effects of clearance joint on impact dynamic characteristics of planar mechanisms," Journal of Vibration and Shock, vol. 36, no. 17, pp. 74-78, 2017.

[5] Z. J. Li, W. L. Yao, and K. W. Song, "Considering the simplified algorithm of planar mechanism with clearance and lubrication," Journal of Dynamics and Control, vol. 16, no. 2, pp. 16-22, 2018.

[6] M. A. B. Abdallah, I. Khemili, and N. Aifaoui, "Numerical investigation of a flexible slider crank mechanism with multijoints with clearance," Multibody System Dynamics, vol. 38, no. 2, pp. 1-27, 2016.

[7] X. L. Chen, S. Jiang, Y. Deng et al., "Dynamics analysis of 2DOF complex planar mechanical system with joint clearance and flexible links," Nonlinear Dynamics, vol. 93, no. 1, pp. 1-26, 2018.

[8] M. Ahmedalbashir, L. Romdhane, and J. Lee, "Dynamics of a four-bar mechanism with clearance and springs-modeling and experimental analysis," Journal of Mechanical Science and Technology, vol. 31, no. 3, pp. 1023-1033, 2017.

[9] Q. Tian, P. Flores, and H. M. A. Lankarani, "Comprehensive survey of the analytical, numerical and experimental methodologies for dynamics of multibody mechanical systems with clearance or imperfect joints," Mechanism and Machine Theory, vol. 122, 2018.

[10] Y. Li, G. Chen, D. Sun, Y. Gao, and K. Wang, "Dynamic analysis and optimization design of a planar slider-crank mechanism with flexible components and two clearance joints," Mechanism and Machine Theory, vol. 99, pp. 37-57, 2016. 
[11] O. Muvengei, J. Kihiu, and B. Ikua, "Dynamic analysis of planar rigid-body mechanical systems with two-clearance revolute joints," Nonlinear Dynamics, vol. 73, no. 1-2, pp. 259-273, 2013.

[12] E. Zheng, R. Zhu, S. Zhu et al., "A study on dynamics of flexible multi-link mechanism including joints with clearance and lubrication for ultra-precision presses," Nonlinear Dynamics, vol. 83, no. 1-2, pp. 137-159, 2016.

[13] S. M. Varedi-Koulaei, H. M. Daniali, M. Farajtabar et al., "Reducing the undesirable effects of joints clearance on the behavior of the planar 3-RRR parallel manipulators," Nonlinear Dynamics, vol. 36, pp. 1-16, 2016.

[14] J. Li, S. Wang, B. Li et al., "Dynamics analysis of square unit and its combined mechanism with joint clearance," Journal of Harbin Institute of Technology, vol. 25, no. 6, pp. 63-69, 2018.

[15] Z. F. Bai and Y. Zhao, "Dynamic behaviour analysis of planar mechanical systems with clearance in revolute joints using a new hybrid contact force model," International Journal of Mechanical Sciences, vol. 54, no. 1, pp. 190-205, 2012.

[16] Z. Wang, Q. Tian, H. Hu, and P. Flores, "Nonlinear dynamics and chaotic control of a flexible multibody system with uncertain joint clearance," Nonlinear Dynamics, vol. 86, no. 3, pp. 1571-1597, 2016.

[17] X. L. Chen, W. H. Gao, S. Jiang et al., "Static and dynamic analysis of a novel single-DOF six bar mechanical press mechanism," Shandong University of Science and Technology, vol. 36, no. 5, pp. 80-90, 2017.

[18] J. Ma and L. Qian, "Modeling and simulation of planar multibody systems considering multiple revolute clearance joints," Nonlinear Dynamics, vol. 90, no. 3, pp. 1907-1940, 2017.

[19] F. Marques, F. Isaac, N. Dourado, A. P. Souto, and P. Flores, "A study on the dynamics of spatial mechanisms with frictional spherical clearance joints," Journal of Computational and Nonlinear Dynamics, vol. 12, no. 5, pp. 1-11, 2017.

[20] X. Wang, G. Liu, and S. Ma, "Dynamic analysis of planar mechanical systems with clearance joints using a new nonlinear contact force model," Journal of Mechanical Science and Technology, vol. 30, no. 4, pp. 1537-1545, 2016.

[21] S. B. Farahan, M. R. Ghazavi, and S. Rahmanian, "Bifurcation in a planar four-bar mechanism with revolute clearance joint," Nonlinear Dynamics, vol. 87, no. 2, pp. 955-973, 2016.

[22] F. Marques, P. Flores, J. C. P. Claro, and H. M. Lankarani, “A survey and comparison of several friction force models for dynamic analysis of multibody mechanical systems," Nonlinear Dynamics, vol. 86, no. 3, pp. 1-37, 2016.

[23] C. S. Koshy, P. Flores, and H. M. Lankarani, "Study of the effect of contact force model on the dynamic response of mechanical systems with dry clearance joints: computational and experimental approaches," Nonlinear Dynamics, vol. 73, no. 1-2, pp. 325-338, 2013.

[24] Y. L. Hou, Y. Wang, M. Y. Li et al., "Chaos identification of two rotational and one translation decoupled parallel mechanism concerning clearance," China Mechanical Engineering, vol. 26, no. 13, pp. 1759-1766, 2015.

[25] E. Zheng, T. Wang, J. Guo et al., "Dynamic modeling and error analysis of planar flexible multilink mechanism with clearance and spindle-bearing structure," Mechanism and Machine Theory, vol. 131, pp. 234-260, 2019.

[26] S. Erkaya, S. Doğan, and Ş. Ulus, "Effects of joint clearance on the dynamics of a partly compliant mechanism: numerical and experimental studies," Mechanism and Machine Theory, vol. 88, pp. 125-140, 2015.
[27] Y. Li, Z. Wang, C. Wang, and W. Huang, "Planar rigid-flexible coupling spacecraft modeling and control considering solar array deployment and joint clearance," Acta Astronautica, vol. 142, pp. 138-151, 2018.

[28] X. Chen, W. Gao, Y. Deng, and Q. Wang, "Chaotic characteristic analysis of spatial parallel mechanism with clearance in spherical joint," Nonlinear Dynamics, vol. 94, no. 4, pp. 2625-2642, 2018.

[29] Y. Chen, Y. Sun, and C. Chen, "Dynamic analysis of a planar slider-crank mechanism with clearance for a high speed and heavy load press system," Mechanism and Machine Theory, vol. 98, pp. 81-100, 2016.

[30] S. W. Hu, X. L. Guo, and Q. Guo, "An improved dissipative contact force model and experimental verification," Journal of Dalian University of Technology, vol. 56, no. 3, pp. 6-14, 2016.

[31] J. F. Huang, T. Yu, and J. Y. Chen, "Comparative analysis of hertz contact force model of rigid body collision," Mechanical Design and Manufacturing, no. 8, pp. 36-38, 2017.

[32] X. Zheng, R. Zhang, and Q. Wang, "Comparison and analysis of two coulomb friction models on the dynamic behavior of slider-crank mechanism with a revolute clearance joint," Applied Mathematics and Mechanics, vol. 39, no. 9, pp. 1239-1258, 2018. 